\title{
Water-Soluble Total Flavonoids Isolated from Isodon Lophanthoides Var.Gerardianus (Benth.) H.Hara Promotes Hepatocellular Carcinoma Sensitivity to 5- Fluorouracil
}

\section{chuan-ping Feng ( $\square$ everyday76@163.com )}

Hunan Traditional Chinese Medical College

\section{Ding hai Xia}

The Affiliated Hospital of Hunan Traditional Chinese Medical College

ying-xin Liu

Hunan Traditional Chinese Medical College

Qing-feng Di

Hunan Traditional Chinese Medical College

Yan Liu

Hunan Traditional Chinese Medical College

Jian Liang

school of pharmaceutical sciences guanzhou university of chinese medicine

Guang-xi Liu

Hunan Traditional Chinese Medical College

\section{Research}

Keywords: Hepatocellular carcinoma, WSTF, 5-FU, ROS

Posted Date: May 27th, 2021

DOI: https://doi.org/10.21203/rs.3.rs-534741/v1

License: (c) (i) This work is licensed under a Creative Commons Attribution 4.0 International License.

Read Full License 
Water-soluble total flavonoids isolated from Isodon lophanthoides var.gerardianus (Benth.) H.Hara promotes hepatocellular carcinoma sensitivity to 5-fluorouracil Feng chuan-ping ${ }^{1}$, Ding hai-xia ${ }^{2}$, Liu ying-xin ${ }^{1}$, Di qing-feng ${ }^{1}$, Liu yan ${ }^{1}$, Liang jian $^{3}$, Liu guang-xi ${ }^{1}$

( ${ }^{1}$ Hunan Traditional Chinese Medical College, Zhuzhou, Hunan, China; ${ }^{2}$ The First Affiliated Hospital of Hunan Traditional Chinese Medical College, Zhuzhou, Hunan, China; ${ }^{3}$ School of Pharmaceutical Sciences, Guangzhou University of Chinese Medicine, Guangzhou, China)

* Corresponding author:

Prof. chuan-ping Feng

E-mail: everyday76@163.com

Telephone: +8618908439690

Fax: +8673128519074 


\section{Abstract:}

Background: Isodon lophanthoides var. gerardianus (Benth.) $\mathrm{H}$. Hara is an autochthonous plant produced chiefly in South China, and as one of mainstream varieties of Xihuangcao, which has been applied for prevention and treatment of common diseases of liver and gall for several hundred years. The water-soluble total flavonoids (WSTF) from the folk herbal medicine has many pharmacological effects. This study investigate whether WSTF has a synergistic effect of combination treatment with 5-fluorouracil (5-FU) on HCC.

Methods: Cells were treated with WSTF alone or combination treatment with 5-FU and we implied cell viability, colony formation assay and cell cycle, reactive oxygen species (ROS), apoptosis analysis and western blot, immunohistochemistry and xenograft tumorigenicity assay for investigating the roles of WSTF on HCC in vitro and in vivo.

Results: WSTF caused G0/G1-phase arrest, and increased ROS levels. The generation of ROS levels could cause cell apoptosis and inhibite colony formation. WSTF decreased the expression of bcl-2, but promoted the expression of bax. These showed that WSTF-mediated apoptosis is associated with mitochondria-dependent. WSTF combined with 5-Fu has a synergistic effect to significantly suppress tumorigenicity both in vitro and in vivo. Reduction of ROS changed the synergistic effect of WSTF and 5-FU

Conclusions: WSTF inhibits the growth of HCC and enhances chemosensitivity to 5-FU in HCC. WSTF combined with 5-FU in HCC can play synergistic effect when applied in the clinical setting.

Keywords: Hepatocellular carcinoma, WSTF, 5-FU, ROS

\section{Background}

Hepatocellular carcinoma (HCC) has become a leading cause of cancer death worldwide (No.2 in China). It is the characteristic of diagnosis in advanced stages, high morbidity and high mortality [1,2], poor prognosis[3], and high rates of recurrence and metastasis[4]. For these reasons, liver cancer patients were forced to accept surgical resection to be the optimal treatment for HCC in China. More unfortunately, recurrence and metastasis created new difficulties for them following surgical treatment. As a result, a number of studies have been conducted to discover novel effective agents to reduce the recurrence and metastasis of the tumor, and to improve symptoms together with patient survival and quality of life.

Isodon lophanthoides var. gerardianus (Benth.) H. Hara belongs to Lamiaceae family [5], and as one of the mainstream varieties of Xihuangcao, this autochthonous plant is produced chiefly in South China. It is one of the traditional Chinese medicine (TCM) herbs extensively utilized to prevent and treat common gall or liver diseases, such as acute cholecystitis and acute jaundice hepatitis [6-8]. Clinical studies showed that prescription based on folk herbal medicine can improve the effective quality of life of HCC patients [9]. Clinical in the treatment of moderate or advanced liver cancer showed also that Isodon lophanthoides var.gerardianus can improve significantly 
patients' general symptoms to prolong their lives [10]. The autochthonous plant is characterized by low toxicity, broad pharmacological activities, including anti-inflammation, anti-oxidation, anticancer, and liver protection[11-19]. Studies showed that the water extracts from traditional Chinese medicine had significant inhibitory effect on HepG2 cell growth in vitro [20,21] and the ethyl acetate extract from the plant had antitumor cell activity[22]. The water extract of the plant can inhibit tumor growth in mice bearing liver cancer H22 [23]. WSTF suppresses HepG2 cell growth [24]. More recently, as suggested in our study, WSTF caused the apoptosis of HepG2 cells by increasing ROS, releasing mitochondrial cytochrome c into the cytoplasma, downregulating Survivin and Bcl-2 levels, decreasing Bax and Caspase-3 levels [25]. Based on the above results, WSTF is the candidate agent to treat HCC.

5-fluorouracil (5-FU) has been extensively utilized to treat HCC [26], colorectal cancer (CRC), and gastric cancer (GC) [27]. 5-FU can arrest the cell cycle as well as the subsequent associated apoptosis, which is related to the inhibition of nucleoside metabolism. The accumulation of ROS in MCF-7 cells enhances the chemosensitivity of 5-FU [28]. WSTF elevates ROS levels in HepG2 cells [25], whether WSTF plays a synergistic effect of 5-FU on HCC is not clear.

In this work, we detected how WSTF affected HCC alone or in combination with 5-FU both in vivo and in vitro. As a result, WSTF enhanced the HCC chemotherapeutic sensitivity to 5-fluorouracil in HCC in vivo and in vitro. WSTF plus 5-FU can play a synergistic effect on HCC when applied in the clinical setting.

\section{Materials and Methods}

\subsection{Herbal medicines and extraction}

Isodon lophanthoides var. gerardianus (Benth.) H.Hara (Batch No.: 20141022) was provided by Guangzhou Baiyun Mountain and Hutchison Whampoa Ltd., and confirmed by Professor Jian-nan Chen from Guangzhou University of Chinese Medicine, China. After appropriately chopped, the proper amounts of medicinal materials were extracted three times with distilled water and filtered. After vacuum concentration and resuspension within distilled water, the HPD-100 macroporous adsorptive resin column, as well as the polyamide column, was used to separate the components successively. Then, we used a vacuum to dry the $30 \%$ ethanol eluate into brown powder (namely, water-soluble total flavonoids, referred to as "WSTF"). Thereafter, high-performance liquid chromatography (HPLC) analysis was performed for WSTF (Fig.1.). There were eight water-soluble components here as follows, vicenin II (3.91 $\mathrm{mg} / \mathrm{g})$, caffeic acid $(0.63 \mathrm{mg} / \mathrm{g})$, schaftoside $(3.01 \mathrm{mg} / \mathrm{g})$, isoschaftoside $(7.18 \mathrm{mg} / \mathrm{g})$, vicenin I $(0.45 \mathrm{mg} / \mathrm{g})$, vitexin $(0.53 \mathrm{mg} / \mathrm{g})$, rutin $(0.54 \mathrm{mg} / \mathrm{g})$ and 6,8-di-C-a-L-arabinosylapigenin $(0.57 \mathrm{mg} / \mathrm{g})$ respectively[25].

\subsection{Cell cultures}

The HepG2 and SMMC7721 cells were provided by Shanghai Institute of Life 
Sciences, Chinese Academy of Sciences (Shanghai, China) and cultivated within the RPMI medium 1640 (Gibco, Grand Island, NY, USA) basic containing 10\% (v/v) fetal bovine serum (FBS, Gibco, Melbourne, Australia), $100 \mathrm{U} / \mathrm{mL}$ penicillin together with $100 \mu \mathrm{g} / \mathrm{mL}$ streptomycin in the humid incubator under at $37{ }^{\circ} \mathrm{C}$ and $5 \% \mathrm{CO}_{2}$ conditions. The medium was renewed two times/week.

\subsection{Cytotoxicity assays}

HepG2 cells $\left(5 \times 10^{3}\right.$ each well $)$, along with SMMC7721 cells $\left(5 \times 10^{3}\right.$ each well $)$ that underwent exponential growth were planted into 96-well plates, respectively, followed by WSTF treatment at various doses for different times, to plot the curve of dose as a function of time. MTT assay was used to assess cell viability. SPSS was employed to calculate IC50.

\subsection{Cell cycle analysis}

HepG2 cells $\left(5 \times 10^{5}\right.$ cells/well $)$ or SMMC-7721 cells $\left(5 \times 10^{5}\right.$ cells/well) achieving logarithmic growth were planted into 6-well plates, followed by $24 \mathrm{~h}$ of serum starving. After $48 \mathrm{~h}$ of WSTF treatment, cells were digested with trypsin and collected, followed by $2 \mathrm{~h}$ of fixation with $70 \%$ ice-cold ethanol. Thereafter, the freshly prepared propidium iodide (PI, $50 \mathrm{mg} / \mathrm{ml}$ ) dye that contained $100 \mathrm{mg} / \mathrm{ml}$ RNase A was used to incubate the cells for $30 \mathrm{~min}$ in accordance with specific protocols (BestBio Biotech Company, Shanghai, China). Then, a total of 20,000 cells from each sample were analyzed using the FACS canto $^{\mathrm{TM}}$ II flow cytometer.

\subsection{Intracellular ROS level}

We applied ROS detection kit to measure intracellular ROS levels. First, HepG2 cells $\left(1 \times 10^{5}\right.$ each well $)$ were planted into 6 -well plates with $24 \mathrm{~h}$ of serum starving. Treated with WSTF with or without $5 \mathrm{mM}$ NAC (N-acetylcysteine) or 5-FU, the HepG2 cell line was subjected to $48 \mathrm{~h}$ of incubation. $100 \mu \mathrm{M}$ DCFH-DA was used to incubate HepG2 cells following specific protocols (Beyotime Biotechnology company, Shanghai, China), and PBS was used to wash for thrice. Finally, the fluorescence intensity was determined by the microplate reader.

\subsection{Apoptosis assay}

HepG2 cells $\left(5 \times 10^{5}\right.$ each well $)$ were inoculated into 6-well plates under $24 \mathrm{~h}$ of serum starving, then WSTF or 5-FU was used to treat HepG2 cells for a period of $48 \mathrm{~h}$, respectively. HepG2 cell line was harvested and dyed using the apoptosis detection kit in accordance with specific protocols (Nanjing Jian Cheng Bioengineering Institute, Nanjing, China), then flow cytometry was applied to analyze 10,000 cells from each sample.

\subsection{Colony formation assay}

Cells at logarithmic growth phase were inoculated into 6-well plates at 500/well. HepG2 cells were exposed to WSTF at the indicated doses or $5 \mathrm{mM}$ NAC for a period of $48 \mathrm{~h}$, respectively. Then, the medium was renewed every two days. Stained with 
$1 \%$ crystal violet, the plates were photographed 12 days later. The Alpha Innotech Imaging system (Alphatron Asia Pte Ltd, Singapore) was used to count colonies from each sample.

\subsection{Western blot analysis}

The HepG2 cell line was harvested and rinsed by PBS. According to the manufacturer's instructions, the RIPA lysis buffer supplemented with the complete protease inhibitor (Roche, Switzerland) was used to lyse HepG2 cells. $25 \mu$ g proteins were incubated and then was isolated onto 12\% SDS-PAGE, followed by transfer onto the PVDF membranes. Thereafter, the 3\% skimmed dry milk powder was used to block PVDF membranes, followed by incubation with the primary antibody at $4{ }^{\circ} \mathrm{C}$ for $12 \mathrm{~h}$ according to the specifications [29]. Later, secondary IgG antibody (goat anti-mouse or anti-rabbit IgG) was used to incubate the membranes for another $2 \mathrm{~h}$. After washing, the ECL kit (Amersham Pharmacia Biotech) was used to react with membranes. In the study, the following antibodies (San Diego, CA, USA) were utilized: PARP, cleaved PARP, Bax, Bcl-2, Cytochrome c, AIF (all dilutions, 1:800), together with beta-actin (1:2000).

\subsection{Efficacy of drug combination}

For evaluating the efficacy of drug combination, we calculated the values of combination index (CI), as well as the values of dose-reduction index (DRI) through using CalcuSyn (Bio Soft Ferguson, MO, USA). CI represents the degree of drug interaction, where $\mathrm{CI}<1$ suggests a synergistic effect, $\mathrm{CI}=1$ represents an additive effect, whereas CI $>1$ represents antagonism. DRI represents a reduced dose of every drug when used in the synergistic combination relative to that used alone at the given effect level. Typically, DRI $>1$ shows a reduction in dosage and toxicity, respectively, after combination treatment.

\subsection{Xenograft tumorigenicity assay}

Male and female athymic BALB/c-nu/nu mice(18-22g;4-6 weeks old) were provided by Laboratory Animal Center of Guangzhou University of Chinese Medicine (Guangzhou, China) and maintained under specific pathogen free conditions. All in vivo studies were carried out following the National Institutes of Health guidelines (NIH publication 86-23, revised 1985). Each experimental protocol related to animal or animal care gained approval from the Ethics Committee of Laboratory Animal Services Center of Guangzhou University of Chinese Medicine (SCXK2013-0034). Humane care was provided for each mouse and their suffering was minimized. After a week, each animal was given a subcutaneous injection of $200 \mu \mathrm{L}$ cell solution, which contained $2 \times 10^{6}$ HepG2 cells at exponential phase, into the oxter. Later, each animal was monitored every day for mental state, bowel function, and diet consumption, while the subcutaneous tumor size (length and width) was determined at intervals of 3 days with Vernier calipers. Then, tumor volume was determined according to $\mathrm{V}_{\text {tumor }}=$ length $\times$ width $^{2} \times 0.5$. On day 6 after inoculation, nude mice were allocated randomly to five groups when the tumor volume was the size of $100 \mathrm{~mm}^{3}$. There were a normal 
control group, model group (blank control group, BC), WSTF group, 5-Fu group, and Combination group, 6 nude mice per group. Intervention was administered in each group as follows: WSTF groups were administered WSTF by gavage according $200 \mathrm{mg} / \mathrm{kg} / \mathrm{d}$, respectively, once daily. 5-Fu group was administered 5-fluorouracil $(5-\mathrm{Fu}, 20 \mathrm{mg} / \mathrm{kg} / \mathrm{d})$ via intraperitoneal injection, twice a week, while NS was administered saline via lavage at some other time. Combination group (WSTF+5-Fu group) was administered WSTF by lavage according $100 \mathrm{mg} / \mathrm{kg} / \mathrm{d}$, and at the same time, also was administered 5-fluorouracil $(5-\mathrm{Fu}, 20 \mathrm{mg} / \mathrm{kg} / \mathrm{d}$ ) via intraperitoneal injection, twice a week. Another 6 nude mice served as a normal control group. After the treatment, researchers observed nude mice every day, weighed every two days, and measured the parameters of tumor growth every three days. Volume was determined based on these data, and the tumor volume growth curve was drawn with time in every group. After an intervention of 24 days, nude mice were sacrificed. Researchers severed carefully the tumor and weighed up for calculating the inhibition rate and tumor weight/body weight ratio, compared with the model group.

\subsection{Immunohistochemistry analysis}

Apoptosis cell death was determined by in situ TUNEL analysis with Cell Death Detection Kit for calculating the apoptosis rate, compared with the model group. Researchers randomly selected five nonoverlapping high magnification horizons $(\times 400)$ to count apoptotic and total cell numbers.

\subsection{Statistical analysis}

GraphPad Prism 5.0 or SPSS 18.0 was employed for all statistical analyses.

Each experiment was carried out in triplicate. Results were expressed in the manner of mean \pm SEM. One-way analysis of variance (ANOVA) was applied in pairwise comparisons between two groups. A difference of $P<0.05$ was deemed statistically significant.

\section{Results}

\subsection{In vitro anticancer activity of WSTF}

The MTT assay was performed to evaluate the cytotoxic effects of WSTF on HepG2 as well as SMMC-7721 cells in vitro. It was illustrated from Fig. 2 that, after WSTF treatment at the indicated doses for 24,48 , and $72 \mathrm{~h}$, the cell numbers reduced depending on the WSTF dose, conforming to prior work [24]. Based on these results of cytotoxicity (IC50) in Table 1, we further investigated apoptosis pathways.

\subsection{WSTF induces G0/G1 phase arrest and increases ROS levels}

We examined how WSTF affected the distribution of cell cycle of HepG2 and SMMC-7721 cells to analyze the mechanism of WFST inhibiting the growth of cancer cells. As described in Fig.3, WSTF treatment led to the decreased proportion of cells at $S$ phase and the increased proportion at G0/G1 phase depending on the WSTF dose. These results indicated that WSTF may interfere with cancer cell growth 
through inducing G0/G1 phase arrest. As shown in Fig.4, WSTF treatment led to increased values of intracellular ROS ( 94.55\%,158.50\%, and $166.20 \%$ in HepG2 cells respectively and $116.95 \%, 192.41 \%$ and $194.68 \%$ in SMMC-7721 cells respectively, in comparison with control). Such results revealed that WSTF increased ROS accumulation.

\subsection{NAC reverses ROS contents and inhibits the WSTF-induced}

\section{activation of mitochondria-dependent apoptosis}

The study is to investigate whether the increase in ROS induced by WSTF resulted in HCC cell apoptosis. After $1 \mathrm{~h}$ of NAC treatment ( $5 \mathrm{mM})$, cells were subjected to $48 \mathrm{~h}$ of WSTF exposure. It was observed from Fig.5 that preliminary NAC exposure resulted in an obvious decrease in ROS levels. This experiment showed that NAC inhibited apoptosis induced by WSTF (Fig.6). Another experiment showed that treatment with NAC clearly inhibited the effect of WSTF on colony formation (Fig.7). In addition, NAC weakened the inhibition of HCC cells by WSTF (Fig.8).

We applied western blot analysis to examine the related mechanisms by which WSTF initiated cell apoptosis. Results showed that WSTF induced decreased antiapoptotic protein (Bcl-2) levels but increased proapoptotic protein (Bax and PARP cleavage) levels (Fig.9A). Experiments showed WSTF weakened the relative cytochrome c band density within the mitochondria fraction, but the opposite tendency was seen within the cytosolic fraction. Besides, the results showed that WSTF increased the activity of cytosolic AIF (Fig.9B). These studies showed that WSTF-caused apoptosis was dependent on mitochondria.

However, NAC eliminated such alterations. We founded out that NAC treatment changed those alterations observed in Bcl-2, Bax, PARP cleavage, and cytochrome $\mathrm{c}$ in the mitochondria fraction induced by WSTF (Fig.9A,9B). Therefore, the findings showed that WSTF-induced mitochondria-dependent apoptosis were closely related to ROS accumulation.

\subsection{WSTF promotes anticancer activity of $5-F U$ in vitro}

To determine how WSTF plus 5-FU affected HCC in vitro, we evaluated the drug combination effects. As described in Fig.10A, there was a synergy in inhibiting the growth of HCC cells after combination of WSTF with 5-FU. CI $<1$ (Fig.10B) and DRI $>1$ (Table2) demonstrated, respectively, the synergistic effect of WSTF combined with 5-FU. That was to say, each drug dose was substantially reduced in the combination treatment relative to that in the single treatment (Table 2). As described in Fig.11, WSTF combined with 5-FU markedly increased the apoptosis in treating HCC compared with 5-FU or WSTF single treatment that resulted in slightly increased apoptosis.

Mechanism research by Western blot analysis also found an obvious increase in the expression of Bax and cleaved PARP after the combination of WSTF and 5-FU, on the contrary, the expression of Bcl-2 was reduced gradually (Fig.11C). The results suggest that WSTF promoted the anticancer activity of 5-FU in vitro by acting as a 
synergistic effect.

\subsection{Combination effects of WSTF plus 5-FU on HCC cell apoptosis}

\section{and colony formation capacity}

For investigating the related mechanisms of WSTF plus 5-FU in inducing apoptosis, this study explored colony formation, changes of ROS levels, and levels of proapoptotic and antiapoptotic proteins. It was illustrated from Fig.12 that the combination of WSTF with 5-FU upregulated apoptosis relative to each drug alone, whereas NAC pretreatment decreased apoptosis. Meanwhile, the combination of WSTF with 5-FU clearly decreased colony formation but significantly elevated ROS levels, but adding NAC weakened the synergy between WSTF and 5-FU (Fig.13A,13B). As shown in Fig.13C mechanism, research by Western blotting further revealed that WSTF plus 5-FU reduced Bcl-2 levels but elevated Bax and PARP cleavage levels, and the addition of NAC strongly recovered the expression levels of anti- or proapoptotic proteins resulting from WSTF and 5-FU. These results suggest that WSTF combined with 5-FU had synergy on HCC cell apoptosis and colony formation through ROS accumulation in vitro.

\subsection{WSTF promotes 5-FU antitumor activity in vivo}

After intervention of 24 days, body weight of mice and the tumor growth curve of tumor volume were drawn, respectively. As shown in Fig.14A, the combination treatment with WSTF and 5-FU made no difference on nude mouse body weight. Studies showed that WSTF combined with 5-FU had significant effects on reducing the weight and volume of HCC tumors, as shown in Fig.14B,14C,14D. Experimental studies have found that nude mice are more thin, lazy to move, eat less, diarrhea in 5 -Fu group because of the side effects of 5-Fu. The most attention is that the combination group has an advantage over 5-Fu group not only the reduction of the tumor weight but also the improvement of the tumor weight/body weight ratio clearly (Fig.14E). These findings implied WSTF combined with 5-Fu in clinical practice could both inhibit tumor cell growth and overcome the side effects of 5-Fu. Compared with vehicle, the results of tumor pathohistologic examination showed that WSTF, 5-Fu, and combination group have obvious changes, respectively, such as tumor cell apoptosis and tissue heavy/medium necrosis (Fig.15A). What is interesting is that the combination group has a more significant increase in TUNEL stained nuclei than WSTF and 5-Fu group (Fig.15B). These findings implied that WSTF combined with 5-FU significantly induced apoptosis, suppressing tumor cell growth while overcoming the side effects of 5-Fu.

\section{Discussion}

Studies showed that WSTF could increase ROS accumulation and promote mitochondrial cytochrome $\mathrm{c}$ release into the cytoplasma, which may be related to the downregulation of Bcl-2 and survivin, whereas the upregulation of Bax and caspase-3[25].Yet most studies have focused on using of WSTF as a potential drug 
alone.

In this experimental study, we investigate whether WSTF has an inhibitory effect on cell growth and promotes the anticancer effect of 5-FU both in vivo and in vitro. Based on these findings, WSTF suppressed cell proliferation through causing cell cycle arrest at G0/G1 phase while inducing mitochondria-dependent apoptosis via ROS accumulation.

Antioxidants can decrease ROS accumulation and relieve further oxidative stress in the cell [30]. In this experiment, $\mathrm{NAC}(\mathrm{N}$-acetylcysteine) was used as a tool drug (a potent antioxidant agent) to investigate the mitochondria-dependent apoptosis induced by WSTF. NAC can maintain the stability of TRX-ASK1 and P38 MAPK pathways [31]. The changes of ROS level and mitochondrial membrane potential are important factors in stimulating apoptosis [32]. Studies showed that the balance between increase and decrease of ROS played an important role in maintaining the normal biochemical state of the body [33] and the changes of ROS in cytoplasmic levels were essential for inhibiting tumor cell growth and development [34]. Our study showed that WSTF downregulated Bcl-2 level but upregulated Bax and PARP cleavage levels. These findings indicated that WSTF stimulated HCC apoptosis through a mitochondria-dependent pathway. The presence of NAC can decrease the influence of WSTF on Bcl-2, PARP cleavage, and Bax levels, respectively. The reduction of NAC could correlate with inhibiting ROS accumulation. These results suggest that the WSTF-induced activation of apoptosis dependent on mitochondria was strongly correlated with the changes of ROS. In addition, WSTF also caused G0/G1 phase arrest. Accordingly, arrest at G0/G1 phase as well as cell apoptosis caused by WSTF are potential mechanisms to inhibit cancer cell proliferation.

In our study, WSTF could increase the accumulation of ROS, so we predicted that WSTF may enhance chemosensitivity to 5-FU through ROS-dependent pathway in the treatment of HCC. 5-FU is recognized as a more effective chemotherapy drug in the treatment of HCC [27,35], and widely used for gastric cancer and colorectal in clinical practice[26]. Compelling evidence showed that the adaptation of cells to ROS stress exerts a vital part in the maintenance of a cell phenotype of cancer and resistance to chemotherapeutic agents [36]. Studies have shown that accumulation of ROS enhanced chemosensitivity to 5-FU in MCF-7 cells [28]. We infer that WSTF may enhance chemosensitivity to 5-FU against HCC. For testifying the above hypothesis, this study calculated DRI and CI values of combination treatment with WSTF and 5-FU to evaluate the feasibility of combination therapy. The study found that there was a synergy in inhibiting the growth of HCC cells after combination of WSTF with 5-FU (CI $<1$ and DRI $>1)$. WSTF combined with 5-FU surely played a significant role in promoting the accumulation of ROS, colony formation suppression, as well as apoptosis induction. Adding NAC reduced the synergy between WSTF and 5-FU by inhibition of colony formation, ROS accumulation, and apoptosis.

Combination of WSTF with 5-FU decreased Bcl-2 level but elevated PARP cleavage and Bax levels, while the addition of NAC strongly recovered resulting from WSTF and 5-FU. These findings indicated that WSTF enhanced chemosensitivity to 5-FU through ROS-dependent pathway. Finally, we used Xenograft tumorigenicity assay to 
testify the synergistic effect on inhibition tumor growth in vivo after the combination of WSTF and 5-FU. Compared with single agents, combined treatment with WSTF and 5-FU significantly decreased tumor volumes that were consistent with the results in vitro. In our experiment, we also found that nude mice are more thin, lazy to move, eat less, diarrhea in 5-Fu group because of the side effects of 5-Fu. Combination group has an advantage over 5-Fu group not only reduction of the tumor weight but also improvement the tumor weight/body weight ratio clearly. These findings implied WSTF combined with 5-Fu in clinical practice could both inhibit tumor cell growth and overcome the side effects of 5-Fu.

\section{Conclusions}

In a word, WSTF inhibits the growth of HCC and enhances chemosensitivity to 5-FU in hepatocellular carcinoma. WSTF plus 5-FU for the treatment of HCC can play a synergistic effect in the clinical application

\section{Abbreviations \\ WSTF: The water-soluble total flavonoids from Isodon lophanthoides var.gerardianus (Benth.) H.Hara}

5-FU: 5-fluorouracil; HCC: Hepatocellularcarcinoma; DRI: Dosereduction index; CI: Combination index; TUNEL: TdT-mediated dUTP Nick-End Labeling; PARP: Poly ADP-ribose polymerase; DCFH-DA: 2, 7-dichlorodihydrofluorescein diacetate.

Authors' contributions

Chuan-ping Feng designed the study, conducted the experiments of cell research, Xenograft tumorigenicity assay, edited and revised the manuscript. Hai-xia Ding was responsible for Preparation of the plant extract. Ying-xin Liu was responsible for Drug combination effects. Qing-feng Di was responsible for statistical analysis. Yan Liu was responsible for western blot analysis. Jian Liang was responsible for Apoptosis detection. Guang-xi Liu was responsible for cell research in vitro. All authors read and approved the final manuscript.

Acknowledgements

Not applicable.

Competing interests

All the authors declared no conflict of interest.

Availability of data and materials

The datasets used and/or analyzed during the current study are available from the corresponding author on reasonable request.

Consent for publication

Not applicable. 
Ethics approval and consent to participate

All in vivo studies were carried out following the National Institutes of Health guidelines (NIH publication 86-23, revised 1985). Each experimental protocol related to animal or animal care gained approval from the Ethics Committee of Laboratory Animal Services Center of Guangzhou University of Chinese Medicine (SCXK2013-0034). Humane care was provided for each mouse and their suffering was minimized.

Funding

This work was funded by the Natural Science Foundation of Hunan province (No. 2019JJ70007).

Author details

${ }^{1}$ Hunan Traditional Chinese Medical College, Zhuzhou, Hunan, China; ${ }^{2}$ The First Affiliated Hospital of Hunan Traditional Chinese Medical College, Zhuzhou, Hunan, China ${ }^{3}$ School of Pharmaceutical Sciences, Guangzhou University of Chinese Medicine, Guangzhou, China;

\section{References}

[1] Jemal A, Murray T, Ward E, Samuels A, Tiwari RC, Ghafoor A, et al. Cancer statistics,2005. CA: A Cancer Journal for Clinicians.2005;55:10-30.

[2] Zender L, Xue W, Zuber J, Semighini CP, Krasnitz A, Ma B, et al. An oncogenomics-based in vivo RNAi screen identifies tumor suppressors in liver Cancer. Cell.2008;135:852-864.

[3] Parkin DM. Global cancer statistics in the year 2000.The Lancet Oncology.2001;2:533-543.

[4] Farazi PA, DePinho RA. The genetic and environmental basis of hepatocellular carcinoma. Discovery Medicine.2006;6:182-186.

[5] Chen JN, Lai XP, Liu N.A Survey on the Botanical Origins of Xihuangcao and the Identification of Its Commercial, Products. Chin Med Mat. 1996;19:73-74.

[6] Wu CY, Li HW. Flora Reipublicae Popularis Sinicae, Science Press. Beijing, China 1977;66:479.

[7] $\mathrm{Xu} Y \mathrm{~L}$, Ma YB, Zhou L, Sun HD. Abietane quinones from Rabdosia Lophanthoides. Phytochemistry 1988;27:3681-3682.

[8] Jiang B, Lu ZQ, Zhang HJ, Zhao QS, Sun HD. Diterpenoids from Isodon lophanthoides. Fitoterapia.2000;71:360-364.

[9] $\mathrm{Hu}$ Y. Professor Chen rui shen' experience introduction in treatment of liver cancer. Journal of New Chinese Medicine.2008;40:12.

[10] Ai WJ, Fu W, Chen BS. Professor Chen rui shen' experience introduction in treatment of moderate or advanced liver cancer. Journal of New Chinese Medicine. 2012;44:142-143.

[11] Liao XZ, Liao HF, Ye MR, Huang GY, Zhou LL, Lai XP. Effects of the water soluble extracts of Isodon Iophanthoides,I,Iophanthoides var. gerardianus and 
I.serra on Anti-inflammation and liver-protection in mice. Chin Med Mat. 1996;19:363-365.

[12] Hu, YJ, Lai, XP, Liu, ZQ, Zhu, YT, Deng, XL, Liu, N, et al. Chemical components of Isodon lophanthoides var. gerardianus and their anti-hepatitis B virus effects. Chin Tradit Herbal Drugs.2005;36:1612-1615.

[13] Lin Y, Kong L. Sudies on the chemical constituents of Desmodium styracifolium (Osbeck) Merr. Asian J Trad Med.2006;1:34-36.

[14] Lin CZ, Zhu CC, Zhong ZY, Rong XL, Xiong TQ. Protective Effect of Isodon lophanthoides var.gerardianus on Hepatic Injury Induced by Concanavalin A in NIH mice. Chin J New Drugs Clin Rem. 2006;17:,325-328.

[15] Nagao Y, Ye MR, Lin CZ, Zhu CC, Lai XP. Protective effect of Isodon lophanthoides var.gerardianus on acute hepatic injury induced by carbon tetrachloride in rats. Chin J Chin Mater Med.2006;31:574-577.

[16] Hou SZ, Nagao Y, Ye MR, Zhu CC, Li G, Lai XP. Protective Effect of Isodon lophanthoides on Acute Hepatic Injury Induced by D-galactosamisne in Rats. Chin Med Mat.2008;31:248-250.

[17] Hou SZ, Liang YM, Zhang J, Huang S, Zhu CC, Lai XP. Studies on Liver-protective and Choleretic Effect of Isodon lophanthoides var.gerardianus. Chin J New Drugs Clin Rem. 2010;21:605-608.

[18] Gong JY, Wu XQ, Zhang Y. Advanced Research of Flavonoid C-Glycosides and Their Pharmacological Effects. Nat Prod Res. 2010;22:525-530.

[19] Zhou CJ, Hou SZ, Li XY, Ye MR, Lai XP. Protective Effect of Isodon lophanthoides var. gerardianus(Benth)H. Hara on Mice Liver Injury Induced by Bacillus Calmette-Guberin Vaccine and LipopoIysaccharide. Chin J New Drugs Clin Rem.2010;21:266-268.

[20] Tang HM, Chen JN, Xu XQ, Lai XP, Huang S. Water-soluble constituents from Isodon lophanthoides var. gerardianus and their antitumor activities. Chin Tradit Herbal Drugs. 2014;45:3219-3223.

[21] Chen YH, Zeng Y, Luo YH. Effect of Rabdosia lophanthoides on the proliferation and apoptosis in hepatoma carcinoma cell line HepG2. Journal of Shandong university (health sciences).2013;51:42-44.

[22] He Y, Li HY, Kang LQ. In vitro screening of effective anti-HBV and anti-tumor compounds from Rabdosia serra(Masim.) Hara. China Journal of Modern Medicine.2011;21:1449-1456.

[23] Zhang WF. Experimental study on tumor-burdened inhibition of liver cancer H22 in mice of Xihuangcao. Acta Chinese Medicine and Pharmacology.2008;28:58.

[24]Zhang Y, Tang HM, Li A, Xu LF, Chen JN, Huang S, et al. Determination of six C-Glycoside flavones and antitumor activity of water-soluble total flavonoide from Isodon lophanthoides var. gerardianus. Chin J Chin Mater Med. 2015;40:1543-1574.

[25] Feng CP, Tang HM, Huang S, Hou SZ, Liang J, Huang W, et al. Evaluation of the effects of the water-soluble total flavonoids from Isodon lophanthoides var.gerardianus (Benth.) H. Hara on apoptosis in HepG2 cell: Investigation of the most relevant mechanisms. Journal of Ethnopharmacology.2016;188:70-79. 
[26] De Lima Lopes G Jr, Dicksey JS, Peters WP, Palalay M and Chang AY. Final results of a prematurely discontinued Phase $1 / 2$ study of eniluracil with escalating doses of 5-fluorouracil administered orally in patients with advanced hepatocellular carcinoma. Cancer Chemother Pharmacol 2011; 68: 1067-1073.

[27] Diasio RB and Johnson MR. The role of pharmacogenetics and pharmacogenomics in cancer chemotherapy with 5-fluorouracil. Pharmacology 2000; 61: 199-203.

[28]Pandey V, Chaube B and Bhat MK. Hyperglycemia regulates MDR-1, drug accumulation and ROS levels causing increased toxicity of carboplatin and 5-fluorouracil in MCF-7 cells. J Cell Biochem 2011; 112: 2942-2952

[29]Nho KJ, Chun JM, Kim HK. Agrimonia pilosa ethanol extract induces apoptotic cell death in HepG2 cells. Journal of Ethnopharmacoloy.2011;138:358-363.

[30]Kim SH, Smith AJ, Tan J, Shytle RD and Giunta B. MSM ameliorates HIV-1 Tat induced neuronal oxidative stress via rebalance of the glutathione cycle. Am $\mathrm{J}$ Transl Res 2015; 7: 328-338.

[31] Hsieh CC and Papaconstantinou J. Thioredoxin-ASK1 complex levels regulate ROS-mediated p38 MAPK pathway activity in livers of aged and long-lived Snell dwarf mice. FASEB J 2006; 20: 259-268.

[32] Whittemore,E.R.,Loo,D.T.,Cotman,C.W. Exposure to hydrogen peroxide induces cell death via apoptosis in cultured rat cortical neurons. neuroreport, 1994.5,1485-1488.

[33] Brunelle, J.K., Chandel, N.S. Oxygen deprivation induced cell death: an update. Apoptosis 2002,7, 475-482.

[34]Ka,H.,Park,H.J.,Jung,H.J.,Choi,J.W.,Cho,K.S.,Ha,J.,Lee,K.T.Cinnamaldehyde induces apoptosis by ROS-mediated mitochondrial permeability transition in human promyelocytic leukemia HL-60 cells. Cancer Letters 2003,196, 143-152.

[35] Chen CT and Hung MC. Beyond anti-VEGF: dual-targeting antiangiogenic and antiproliferative therapy. Am J Transl Res 2013; 5: 393-403.

[36] Pervaiz S and Clement MV. Tumor intracellular redox status and drug resistance-serendipity or a causal relationship? Curr Pharm Des 2004; 10: 1969-1977. 
Fig.1

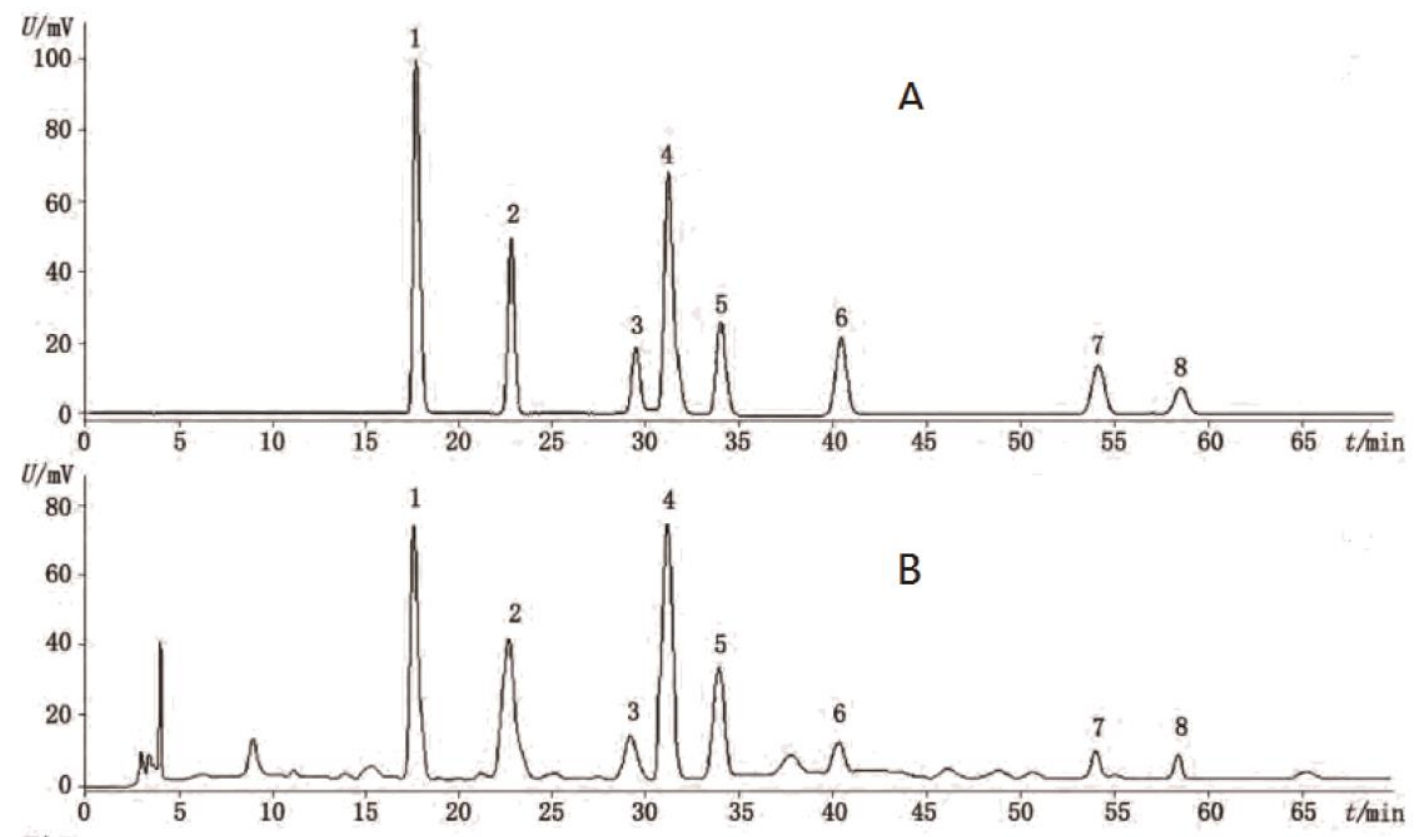

Fig.1 High performance liquid chromatography of standard reference and WSFT samples A. a mixture of standard references B. WSTF

1.caffeic acid 2. vicenin II 3.vicenin III 4.isoschatroside 5.schaftoside 6. vitexin 7.6,8-di-C-a-L-arabinosylapigenin 8 . rutin

Fig.2
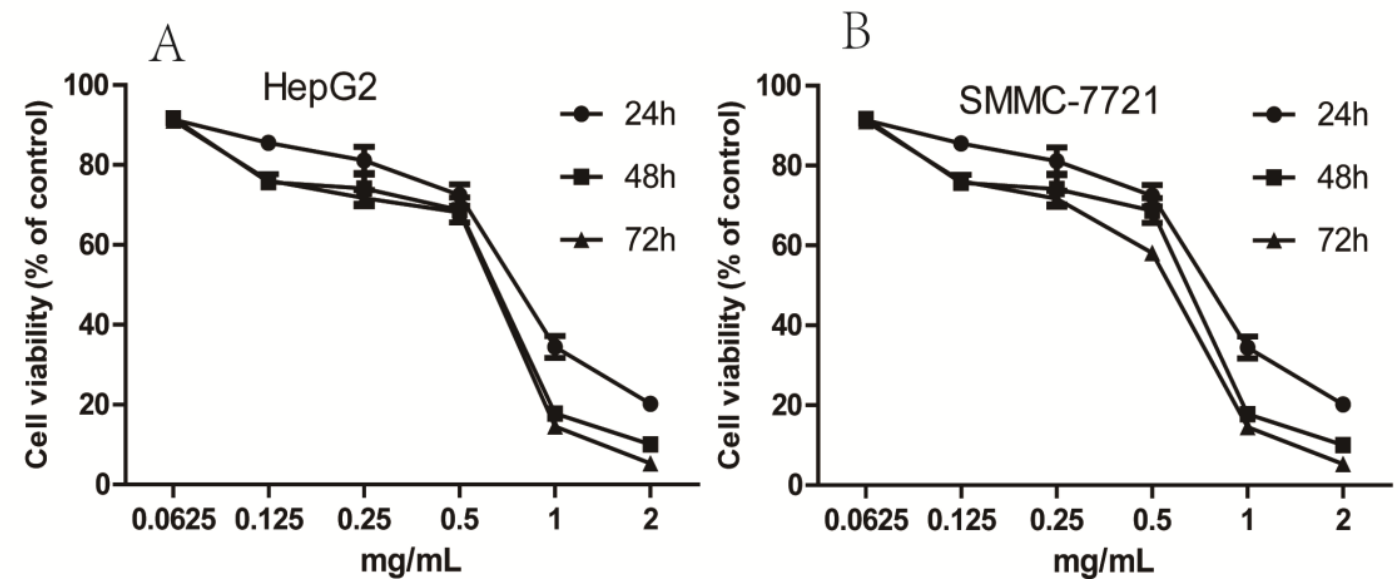

Fig.2 WSTF inhibits cancer cell proliferation in HepG2 and SMMC-7721 cells.

Inhibitory effects of WSTF on the growth of cancer cells depending on the dose. MTT assay was carried out in cells exposed to WSTF for 24,48 , and $72 \mathrm{~h}$. The results are presented in the manner of mean \pm SEM from 3 independent tests. $* P<0.05$, compared with vehicle-exposed controls. 
Fig3.
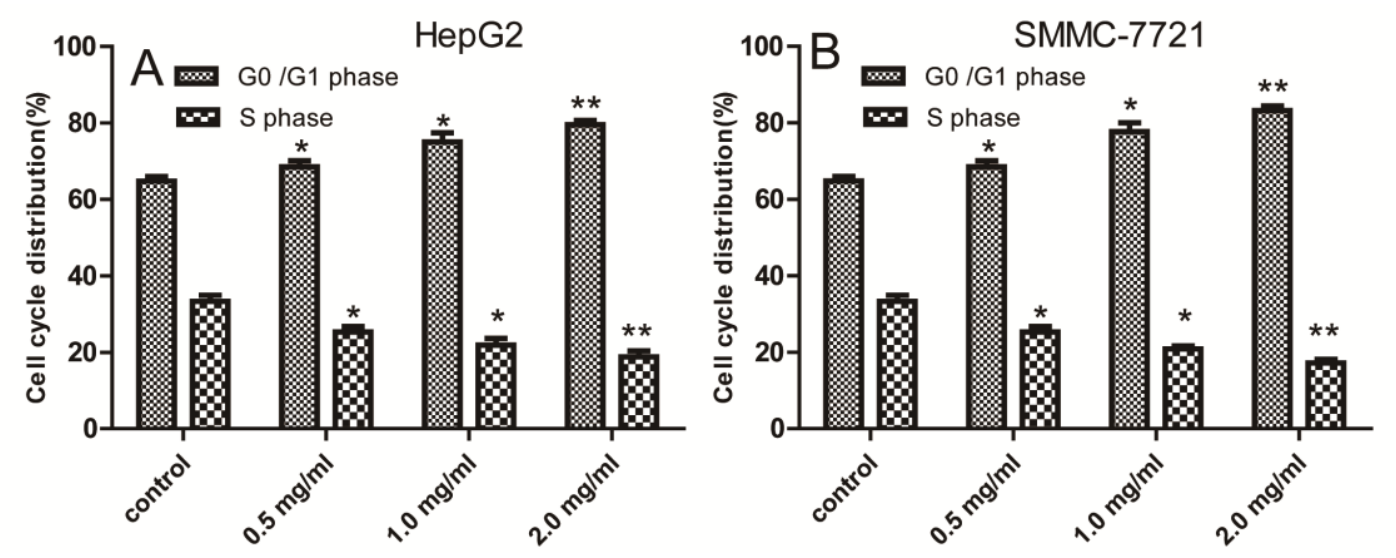

Fig3. WSTF induces G0/G1-phase arrest.

All results were presented in the manner of mean \pm SEM from 3 independent tests. $* P<0.05, * * P<0.01$ relative to controls.

Fig4.
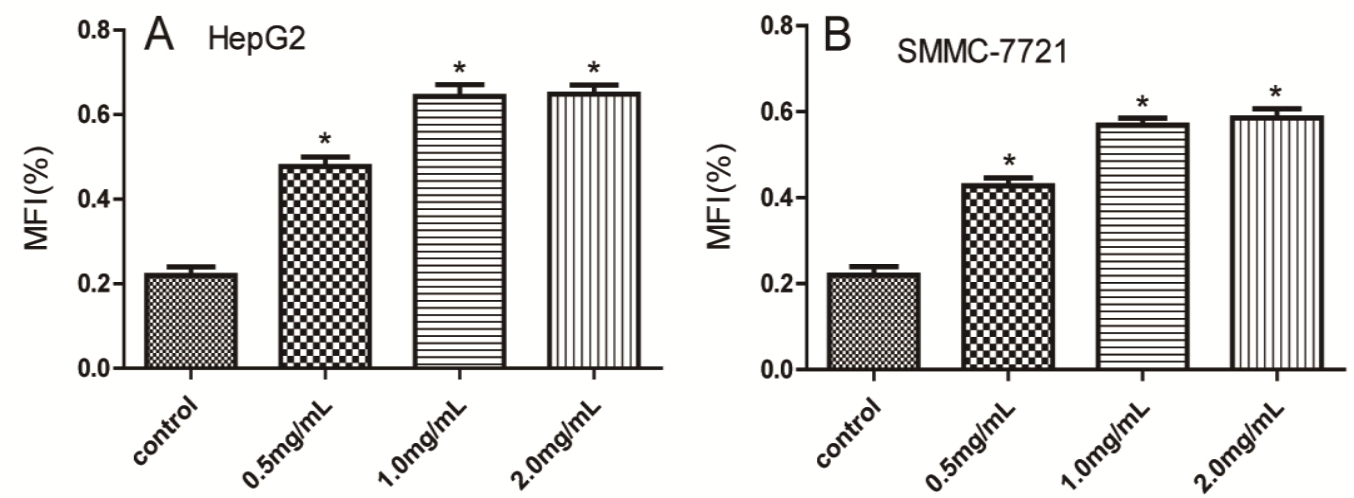

Fig4. Effect of WSTF on ROS accumulation in SMMC-7721 and HepG2 cell lines. All results are presented in the manner of mean \pm SEM from 3 independent tests. $* * P<0.01$ compared with controls. 
Fig5.
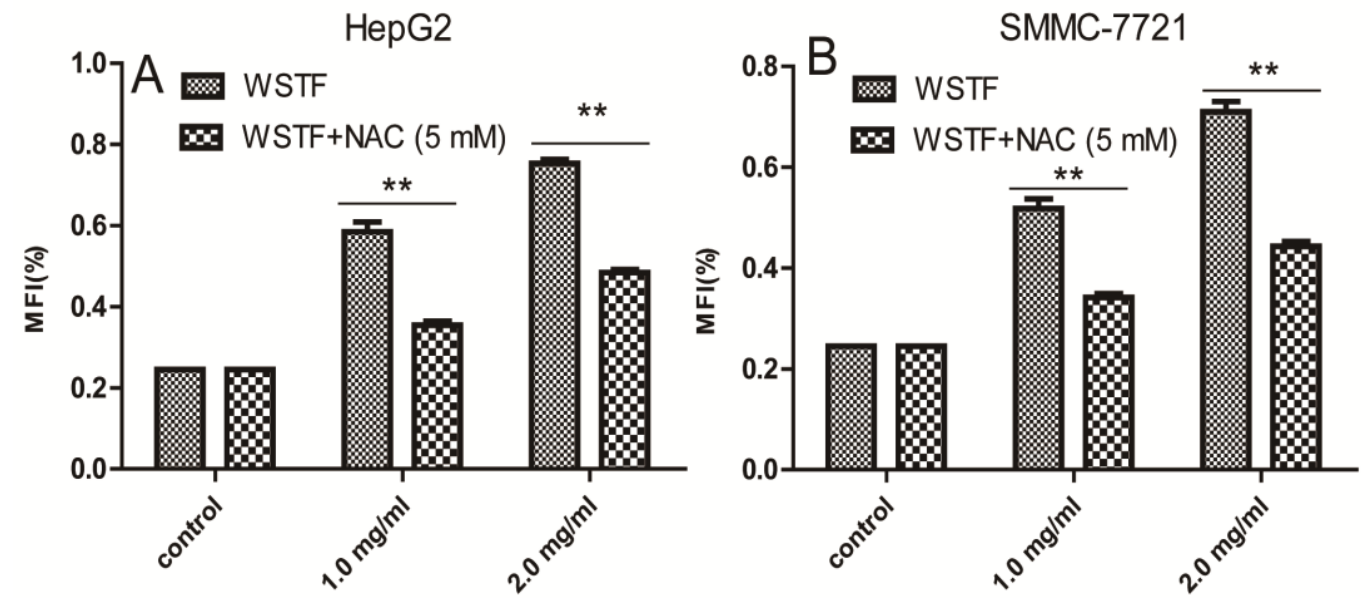

Fig5. NAC inhibits the effect of WSTF on ROS accumulation in HepG2 and SMMC-7721 cell lines.

Following $1 \mathrm{~h}$ of NAC treatment, cells were exposed to WSTF for $48 \mathrm{~h}$. All results are expressed in the manner of mean \pm SEM from 3 independent tests. $* P<0.05$, $* * P<0.01$ compared with controls.

Fig6.
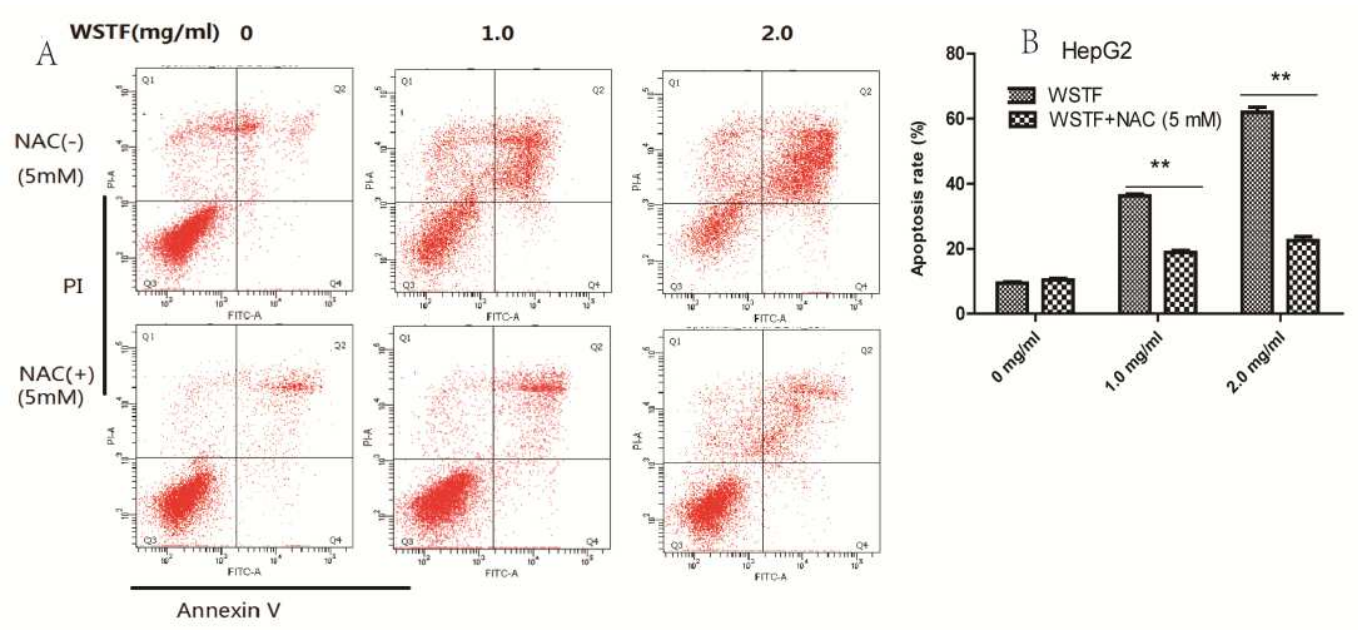

Fig6. NAC inhibits apoptosis of HepG2 cells induced by WSTF

All results are presented in the manner of mean \pm SEM from 3 independent tests. $* P<0.05, * * P<0.01$ relative to controls. 
Fig7.

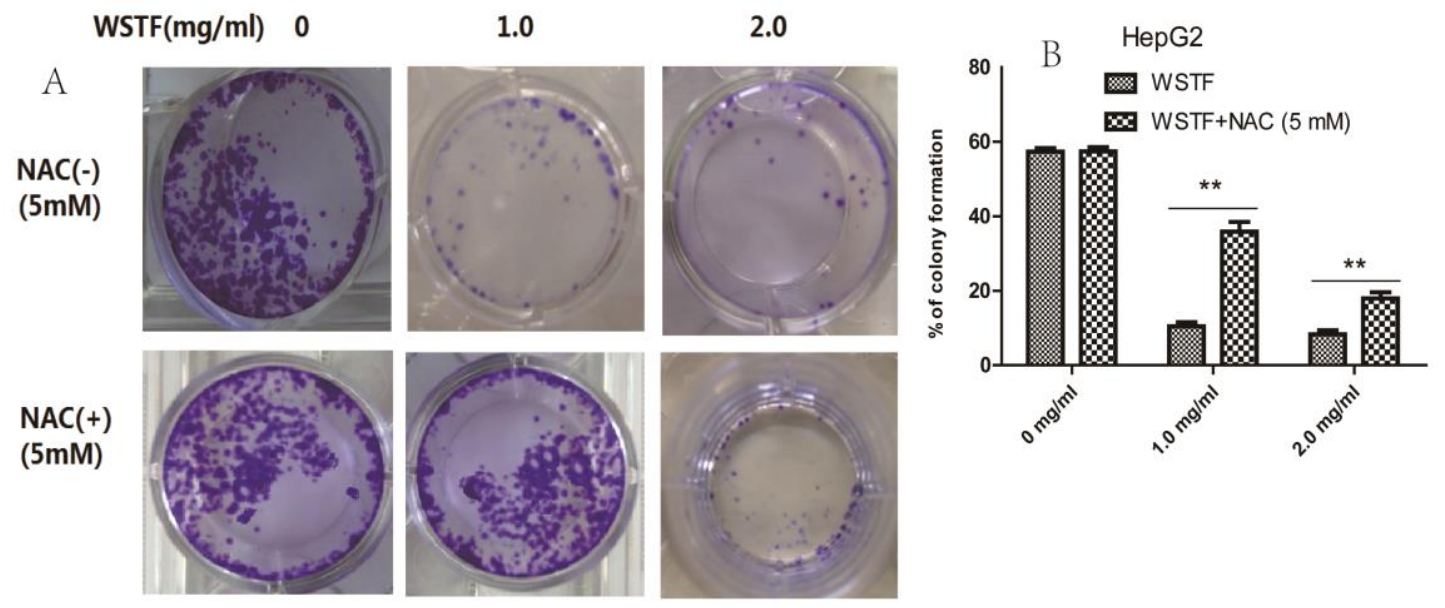

Fig7. NAC inhibits the effect of WSTF on colony formation of HepG2 cells.

After $1 \%$ crystal violet staining, each plate was photographed after 12 days. Then, the colony percentage was determined.

Fig8.
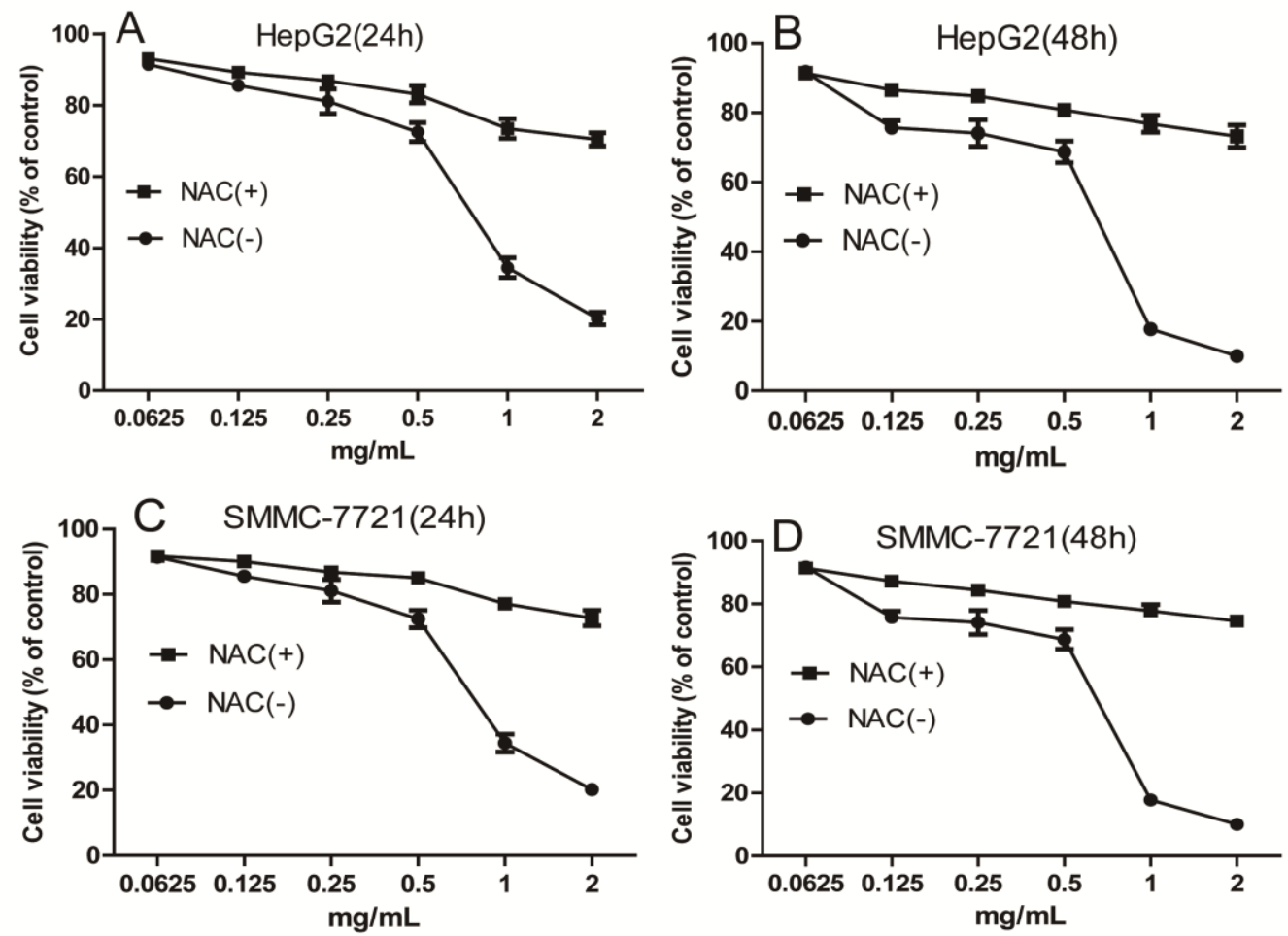

Fig8. NAC weakens the inhibition of WSTF on cancer cell growth in HepG2 and SMMC-7721 cells

After $1 \mathrm{~h} \mathrm{NAC}$ treatment, cells were exposed to WSTF treatment for 24 and $48 \mathrm{~h}$, respectively. All results are expressed in the manner of mean \pm SEM from 3 independent tests. $* P<0.05$, $* * P<0.01$ compared with controls. 
Fig9.

A

bcl-2

bax

PARP

Cle-PARP

$\beta$-actin

WSTF(mg/ml)

$\mathrm{NAC}(5 \mathrm{mM})$
B
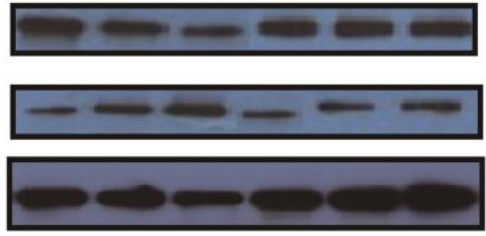

Cytosolic Cytochrome $C$

Cytosolic AIF

B-actin

WSTF(mg/ml)

$\operatorname{NAC}(5 \mathrm{mM})$
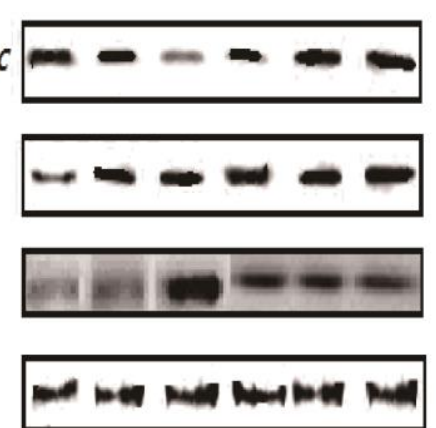

$\begin{array}{llllll}0 & 1.0 & 2.0 & 0 & 1.0 & 2.0\end{array}$

- -+++

Fig9. NAC inhibits the effect of WSTF on pro- and anti-proptotic protein levels. After $1 \mathrm{~h}$ of NAC pretreatment, HepG2 cells were exposed to WSTF for $48 \mathrm{~h}$.

Fig10.
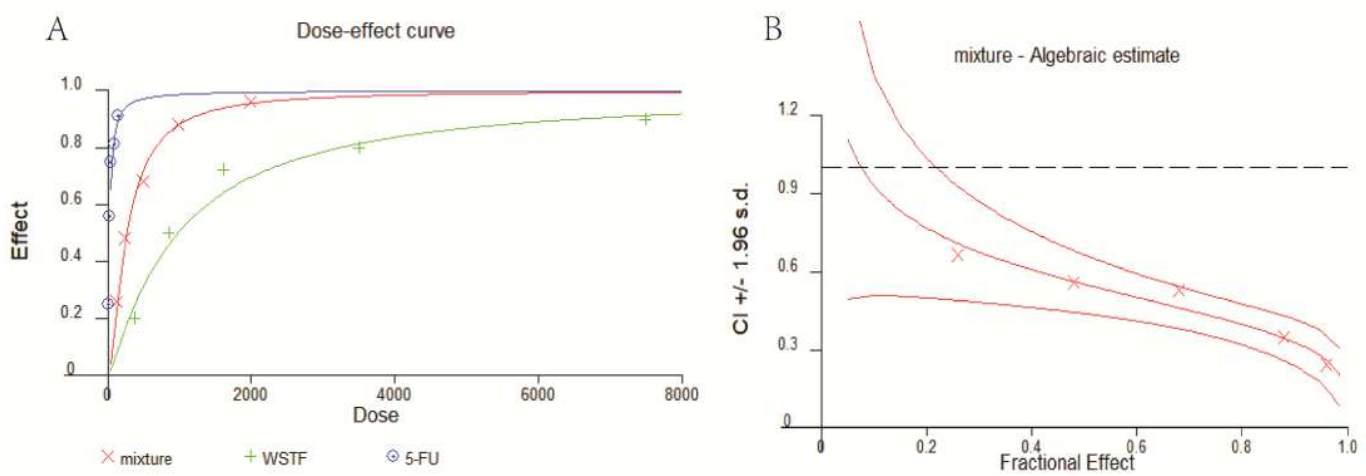

Fig10. WSTF promotes 5-FU anticancer activity in vitro.

A. 3000 cells/well were treated with WSTF plus 5-FU for MTT assay. The inhibition rates of WSTF and 5-FU on HepG2 cells were calculated

B. CI values were calculated by CalcuSyn2.0. 
Fig11.

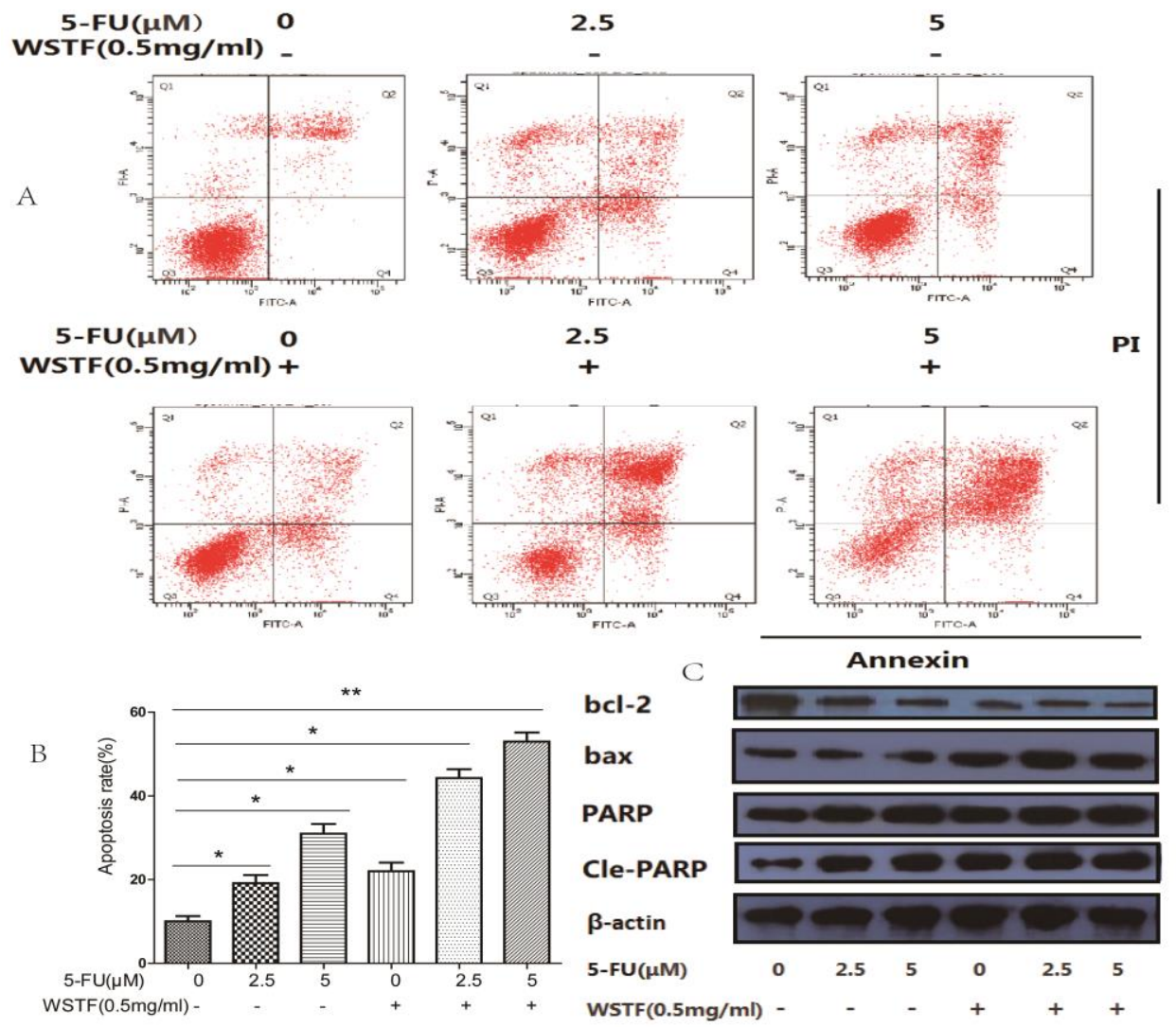

Fig11. Combination of WSTF with 5-FU induces apoptosis.

A. HepG2 cells were subjected to Annexin V/PI staining for evaluating the WSTF and/or 5-FU-induced apoptosis.

B. Cell apoptosis percentage were expressed in the manner of mean \pm SEM from 3 independent tests.

C. The expression of apoptosis-related proteins through Western blotting. $* P<0.05, * * P<0.01$. 
Fig12.
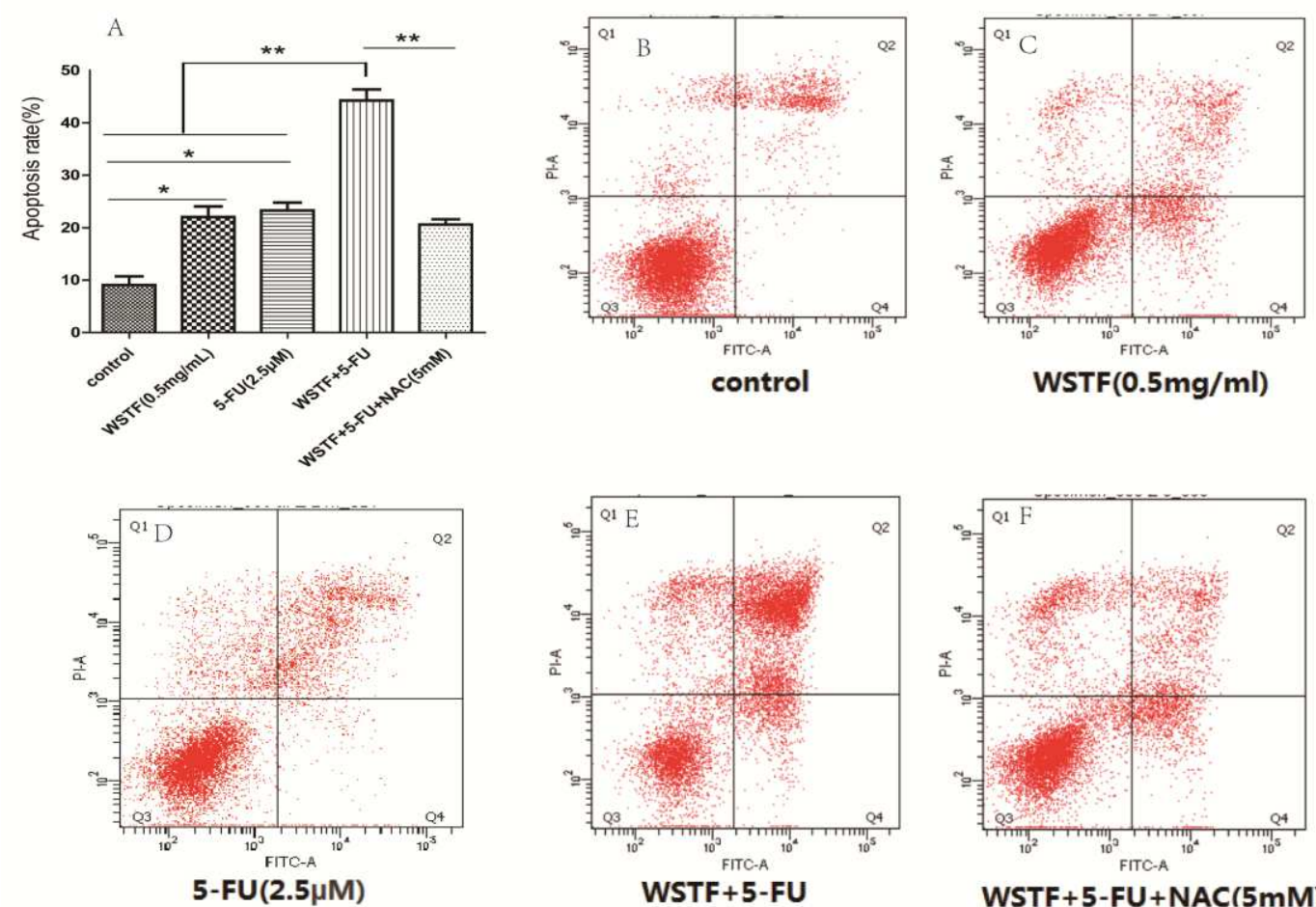

Fig12. NAC inhibits the impact of WSTF plus 5-FU on apoptosis.

HepG2 cells were subjected to Annexin V/PI staining for evaluating apoptosis induced by WSTF plus 5-FU with or without NAC.

Fig13.

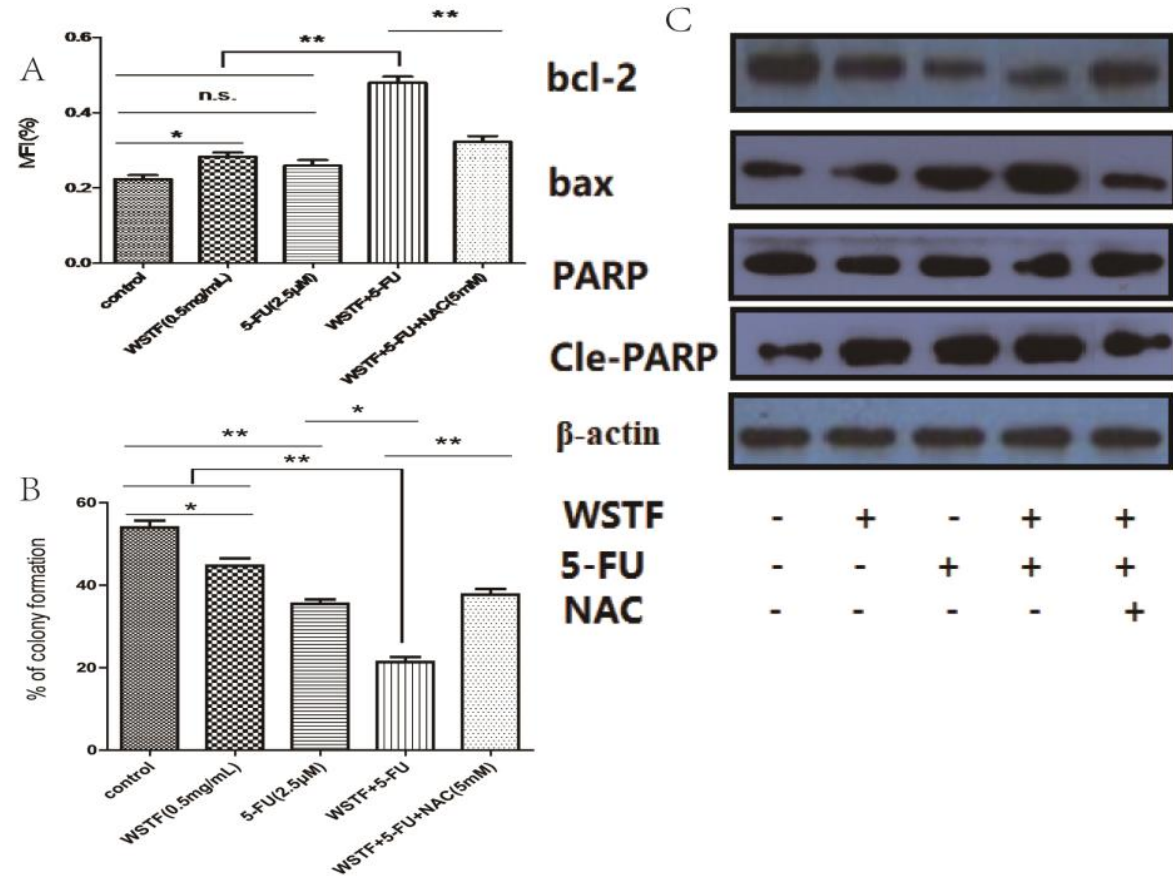

Fig13. NAC inhibits the impact of WSTF plus 5-FU on ROS accumulation, colony formation, and apoptosis-related protein expression within HepG2 cells.

A. After $48 \mathrm{~h}$ of incubation with WSTF and 5-FU with or without NAC, 
ROS level in HepG2 cells was determined by DCFH-DA, and the relative intensity of average fluorescence is presented in the manner of mean \pm SEM from 3 independent tests.

B. After $48 \mathrm{~h}$ of incubation with WSTF and 5-FU with or without NAC,

After $1 \%$ crystal violet staining, each plate was photographed after 10 days. Colony percentage was determined and presented in the manner of mean \pm SEM from 3 independent tests.

C. After $48 \mathrm{~h}$ of incubation with WSTF and 5-FU with or without NAC, The expression of apoptosis-related proteins by Western blotting.

$* P<0.05, * * P<0.01$.

Fig14.
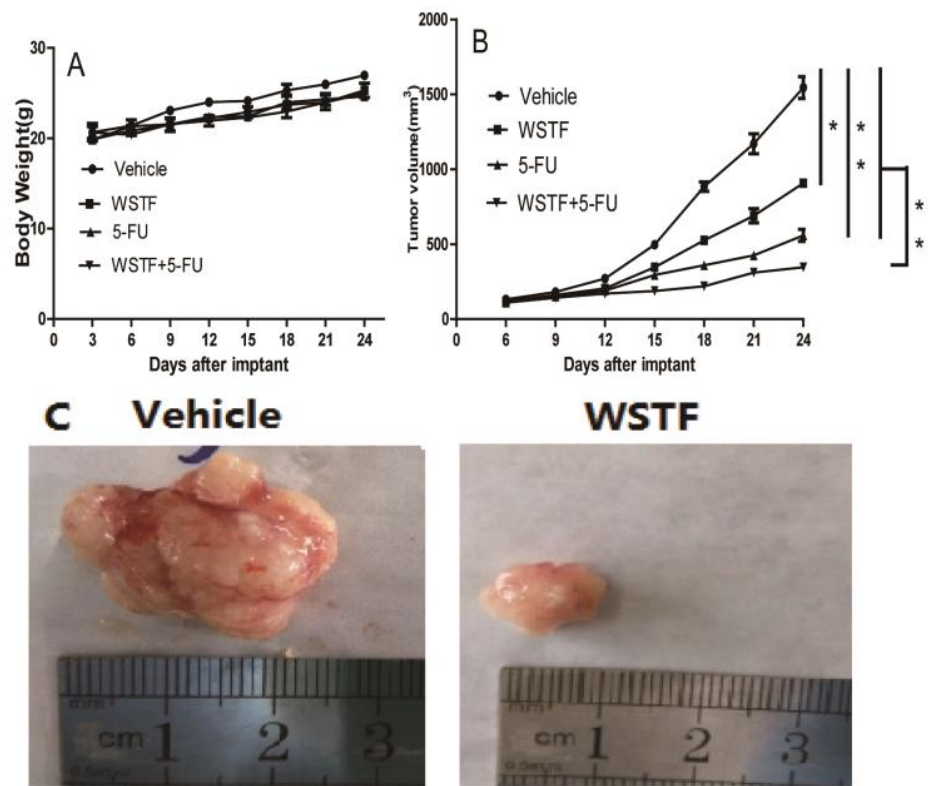

WSTF
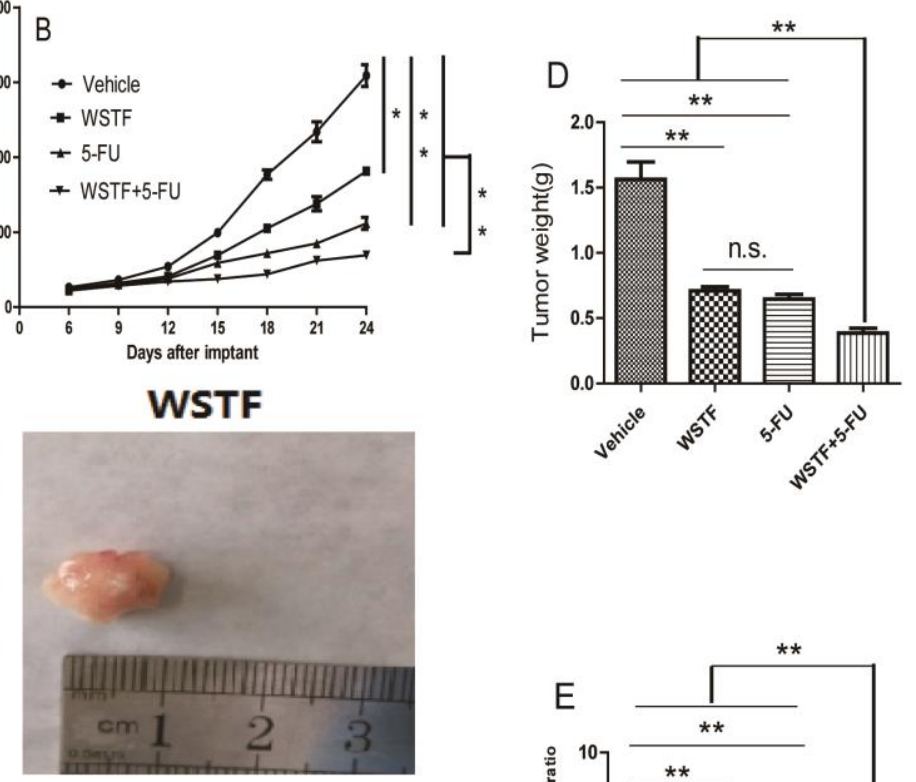

5-FU
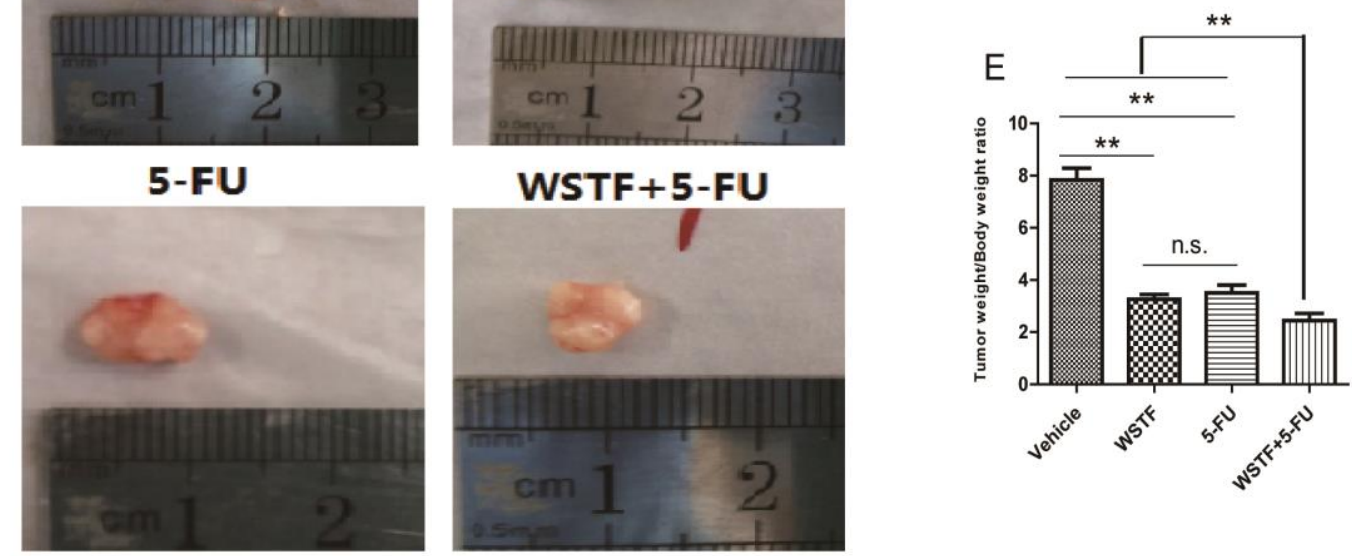

Fig14. WSTF promotes anticancer activity of 5-FU in vivo

A. Body weight curves of mice in each group. Combination treatment with WSTF and 5-FU did not affect the nude mouse body weight

B. Xenograft growth curve. Subcutaneous injection of HepG2 cells was given to mice through oxter (xenograft volume was determined at intervals of 3 days) and drug administration started.

C. The specimen of xenografts among four groups.

D. Tumor weights of four groups.

E. Tumor /body weight ratio in the four groups. 
Results are expressed in the manner of mean \pm SEM from 3 independent tests. $* P<0.05, * * P<0.01$, n.s. no significance.

Fig15.
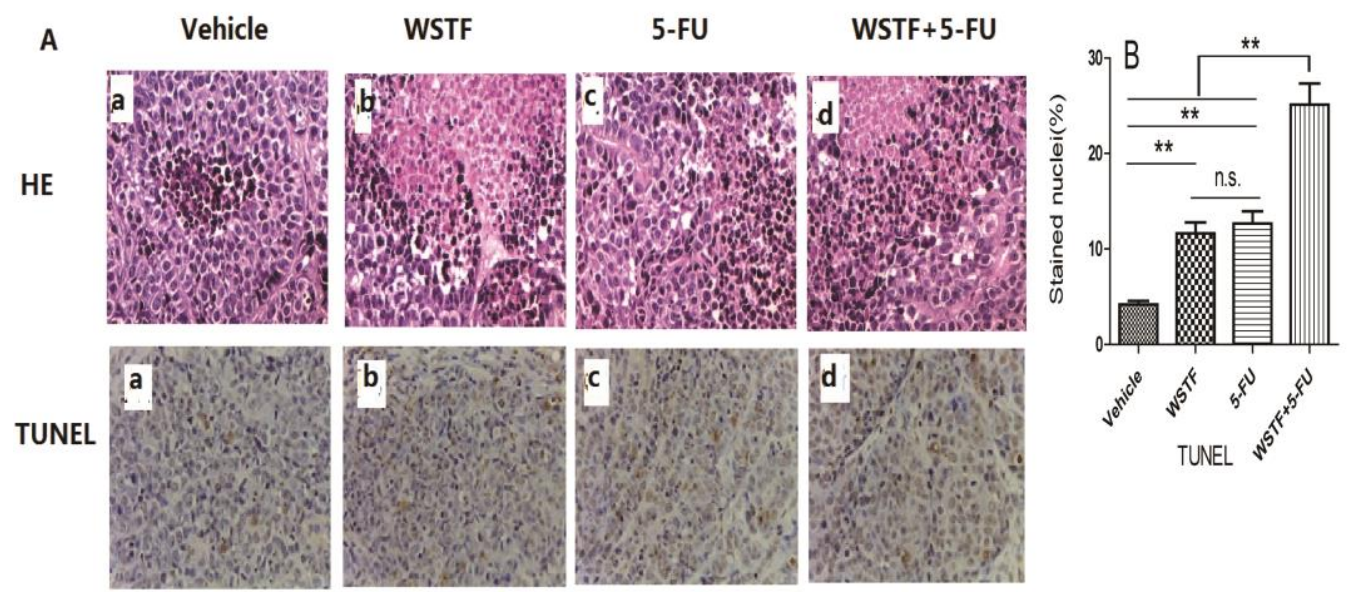

Fig15. H\&E staining.

A. Hematoxylin of HepG2 cell xenografts in nude mice (HE×200) and TUNEL assay ( $\times 40)$ for xenografts.

B. TUNEL stained nucleus percentage was used to evaluate apoptosis by TUNEL staining.

Results are expressed in the manner of mean \pm SEM from 3 independent tests.

$* P<0.05, * * P<0.01$, n.s. no significance.

Table 1 Cytotoxicity of WSTF against normal human cells and tumor cells

\begin{tabular}{llc}
\hline Cells & time(h) & $\mathrm{IC}_{50}(\mathrm{mg} / \mathrm{mL})$ \\
\hline HepG2 & 24 & $0.52 \pm 1.56$ \\
& 48 & $0.42 \pm 1.33$ \\
SMMC-7721HCC & 24 & $0.36 \pm 0.96$ \\
& 48 & $0.73 \pm 1.43$ \\
& 72 & $0.59 \pm 2.62$ \\
\hline
\end{tabular}

Cells $\left(5 \times 10^{4} / \mathrm{ml}\right)$ were subjected to WSTF treatment at different doses under $37^{\circ} \mathrm{C}$ and $5 \% \mathrm{CO}_{2}$ conditions for 24,48 , and $72 \mathrm{~h}$, respectively. The cytotoxicity of WSTF was determined through MTT assay, which was presented in the manner of $50 \%$ inhibitory concentration (IC50). Data in each typical experiment were obtained from 3 independent tests. 
Table 2 Effect of WSTF plus 5-FU on HepG2 cells

\begin{tabular}{|c|c|c|c|c|c|c|c|}
\hline \multicolumn{2}{|c|}{ Combination } & \multicolumn{2}{|c|}{ Drug alone } & \multirow[t]{2}{*}{$\mathrm{Fa}$} & \multirow[t]{2}{*}{$\mathrm{Cl}$} & \multicolumn{2}{|c|}{ DRI } \\
\hline $\begin{array}{l}\text { WSTF } \\
(\mathrm{mg} / \mathrm{m}\end{array}$ & $\begin{array}{l}\text { 5-FU } \\
\text { L) }(\mu \mathrm{M})\end{array}$ & $\begin{array}{l}\text { WSTF } \\
(\mathrm{mg} / \mathrm{mL}\end{array}$ & $\begin{array}{l}5-F U \\
(\mu \mathrm{M})\end{array}$ & & & $\begin{array}{l}\text { WSTF } \\
(\mathrm{mg} / \mathrm{mL})\end{array}$ & $\begin{array}{c}5-\mathrm{FU} \\
(\mu \mathrm{M})\end{array}$ \\
\hline 0 & 0 & 0 & 0 & & & & \\
\hline 0.125 & 2.5 & $0.40 \pm 0.14$ & $7.20 \pm 0.52$ & $0.26 \pm 0.02$ & $0.66 \pm 0.15$ & $3.16 \pm 0.62$ & $2.88 \pm 0.38$ \\
\hline 0.25 & 5 & $0.91 \pm 0.34$ & $17.58 \pm 3.34$ & $0.48 \pm 0.05$ & $0.56 \pm 0.17$ & $3.65 \pm 0.77$ & $3.52 \pm 0.87$ \\
\hline 0.50 & 10 & $1.88 \pm 0.63$ & $38.00 \pm 4.84$ & $0.68 \pm 0.08$ & $0.53 \pm 0.14$ & $3.76 \pm 0.95$ & $3.80 \pm 0.85$ \\
\hline 1.00 & 20 & $5.49 \pm 1.03$ & $119.42 \pm 6.37$ & $0.88 \pm 0.09$ & $0.35 \pm 0.06$ & $5.49 \pm 1.34$ & $5.97 \pm 0.94$ \\
\hline 2.00 & 40 & $15.32 \pm 2.32$ & $357.37 \pm 33.72$ & $0.96 \pm 0.07$ & $0.24 \pm 0.08$ & $7.66 \pm 1.26$ & $8.93 \pm 1.04$ \\
\hline
\end{tabular}

$\mathrm{Fa}$, is the fraction affected by the dose. 
Figures

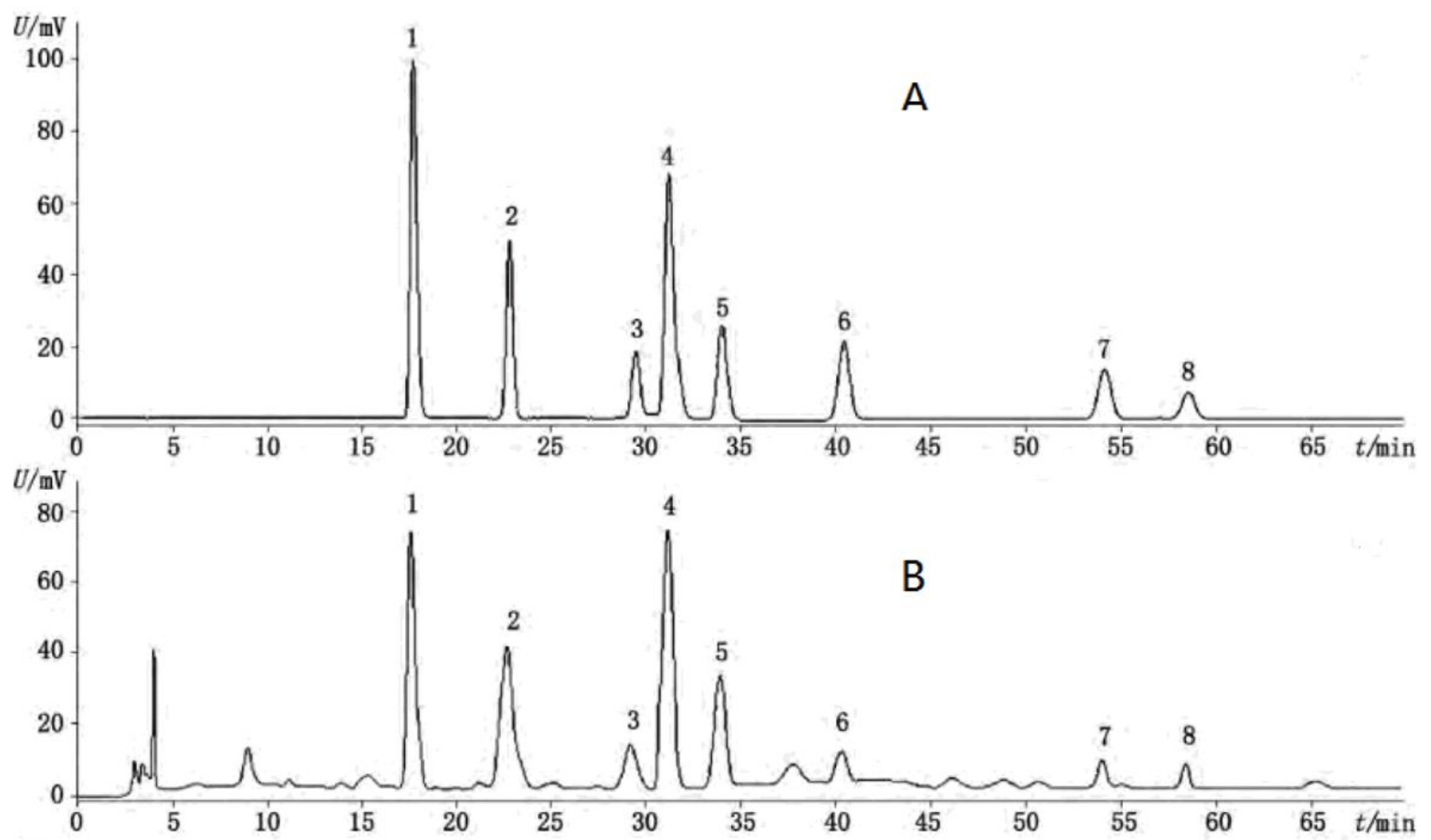

Figure 1

High performance liquid chromatography of standard reference and WSFT samples A. a mixture of standard references B. WSTF 1.caffeic acid 2. vicenin.3.vicenin .4.isoschatroside 5.schaftoside 6. vitexin 7.6,8-di-C-a-L-arabinosylapigenin 8. rutin
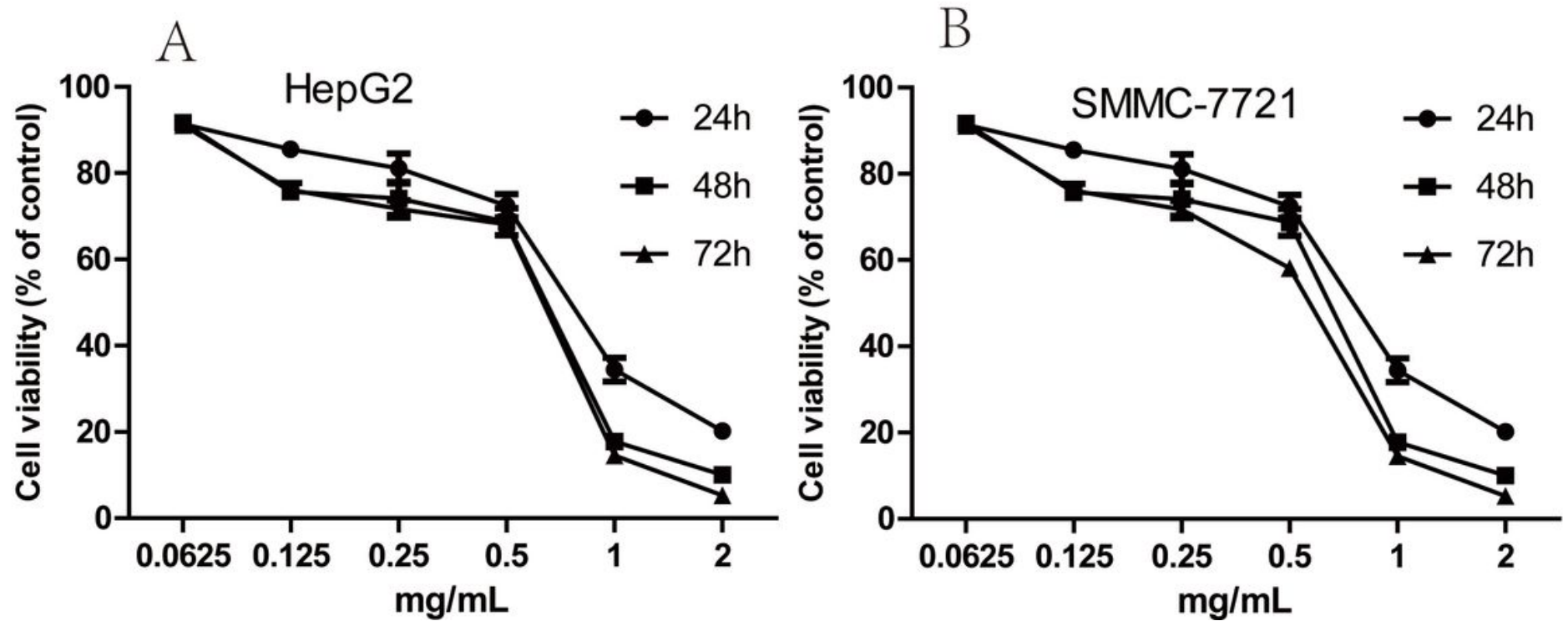
Figure 2

WSTF inhibits cancer cell proliferation in HepG2 and SMMC-7721 cells. Inhibitory effects of WSTF on the growth of cancer cells depending on the dose. MTT assay was carried out in cells exposed to WSTF for 24,48 , and $72 \mathrm{~h}$. The results are presented in the manner of mean \pm SEM from 3 independent tests. ${ }^{*} \mathrm{P}<0.05$, compared with vehicle-exposed controls.
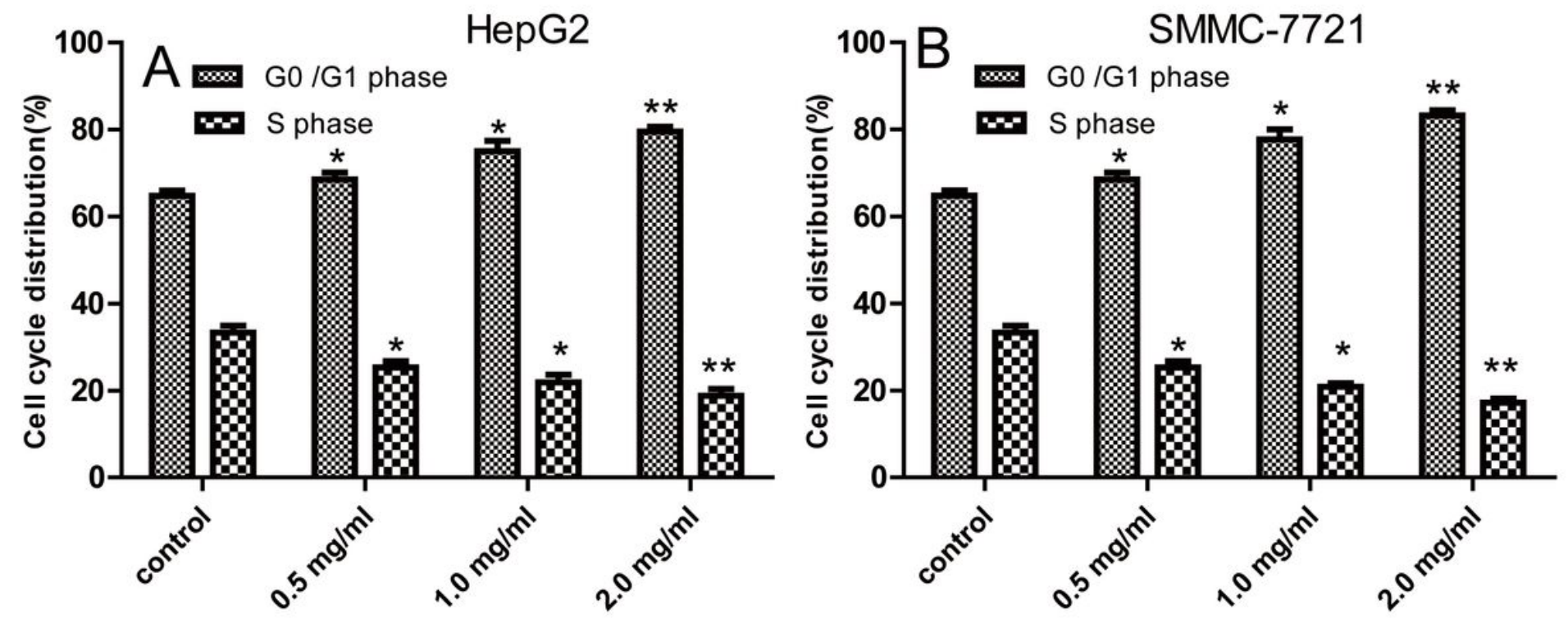

Figure 3

WSTF induces G0/G1-phase arrest. All results were presented in the manner of mean \pm SEM from 3 independent tests. ${ }^{*} \mathrm{P}<0.05,{ }^{*} \mathrm{P}<0.01$ relative to controls.
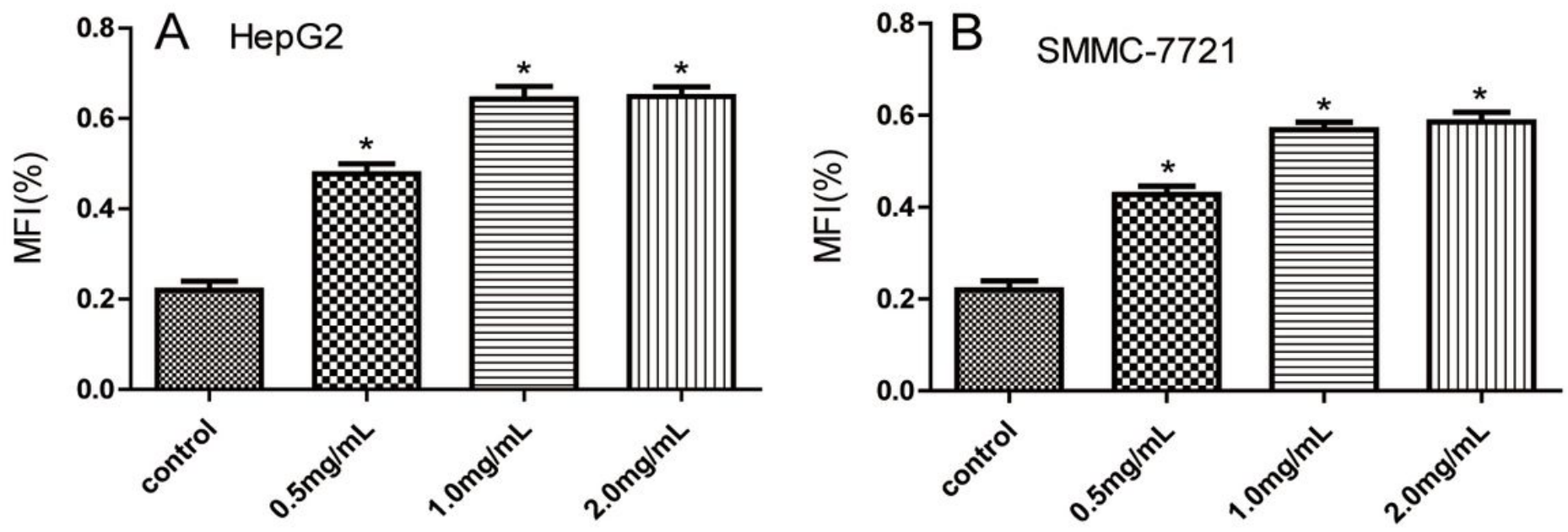

Figure 4

Effect of WSTF on ROS accumulation in SMMC-7721 and HepG2 cell lines. All results are presented in the manner of mean \pm SEM from 3 independent tests. ${ }^{\star \star} P<0.01$ compared with controls. 


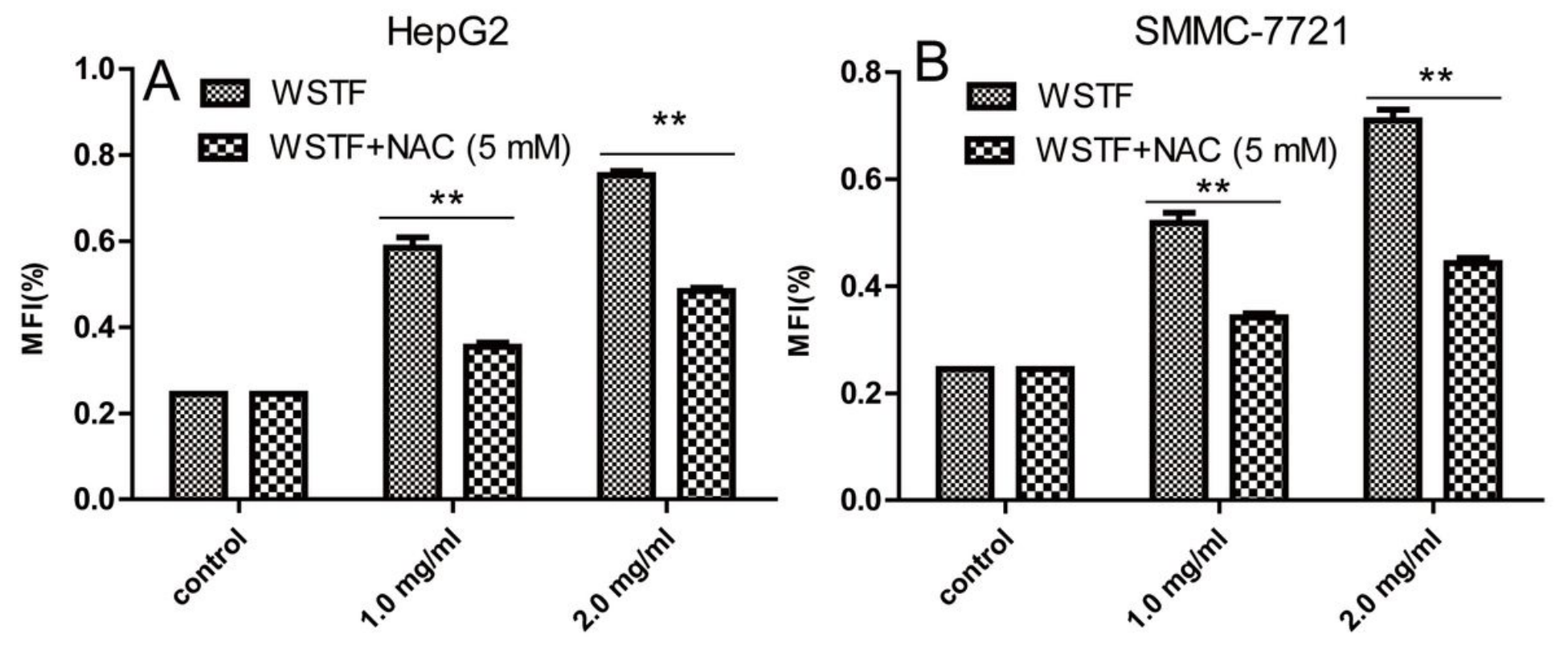

Figure 5

NAC inhibits the effect of WSTF on ROS accumulation in HepG2 and SMMC-7721 cell lines. Following $1 \mathrm{~h}$ of NAC treatment, cells were exposed to WSTF for $48 \mathrm{~h}$. All results are expressed in the manner of mean \pm SEM from 3 independent tests. ${ }^{*} \mathrm{P}<0.05,{ }^{*} \mathrm{P}<0.01$ compared with controls.

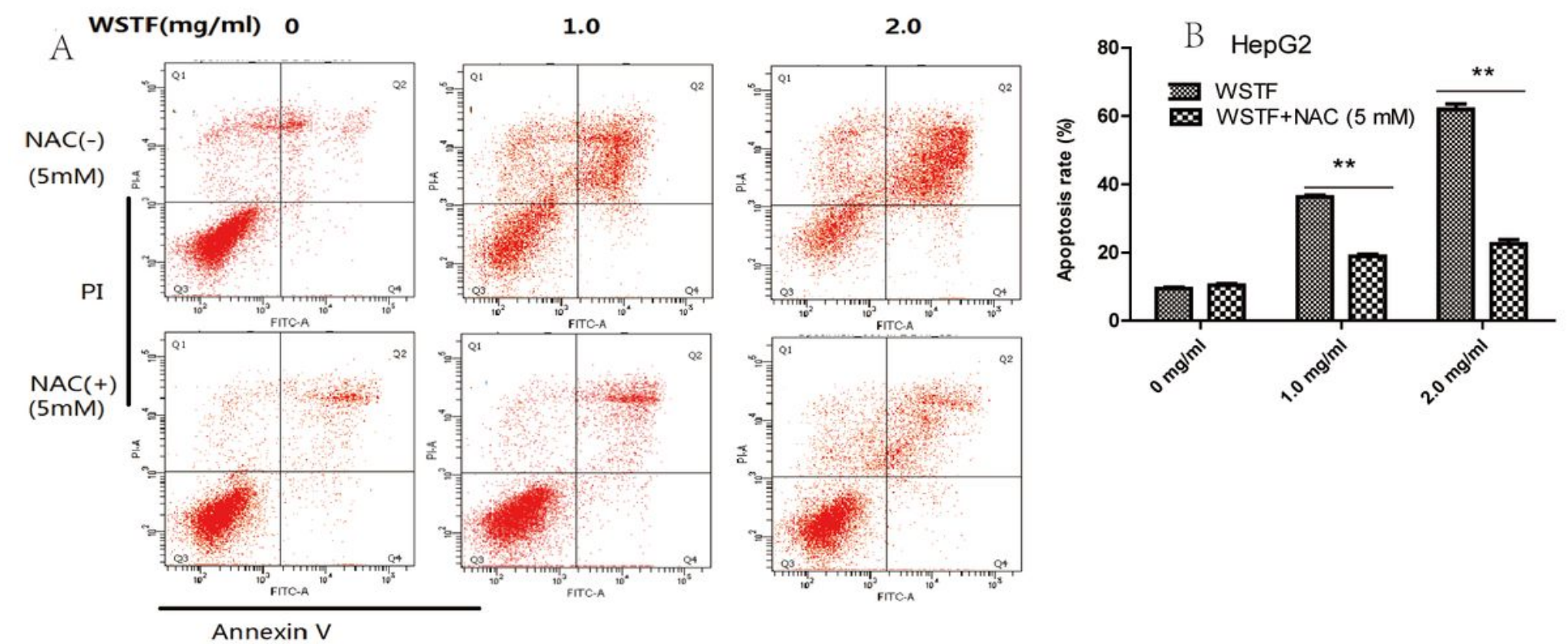

Figure 6

NAC inhibits apoptosis of HepG2 cells induced by WSTF All results are presented in the manner of mean \pm SEM from 3 independent tests. ${ }^{*} \mathrm{P}<0.05,{ }^{*} \mathrm{P}<0.01$ relative to controls. 


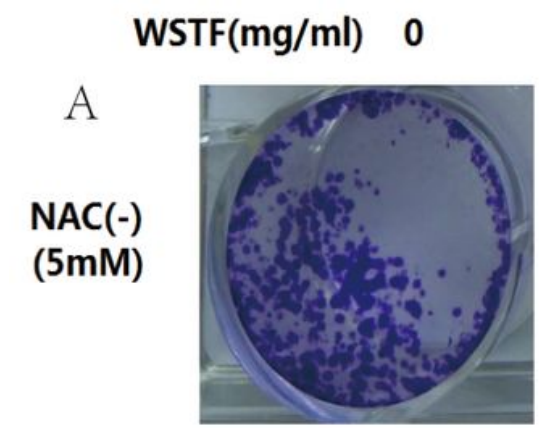

1.0
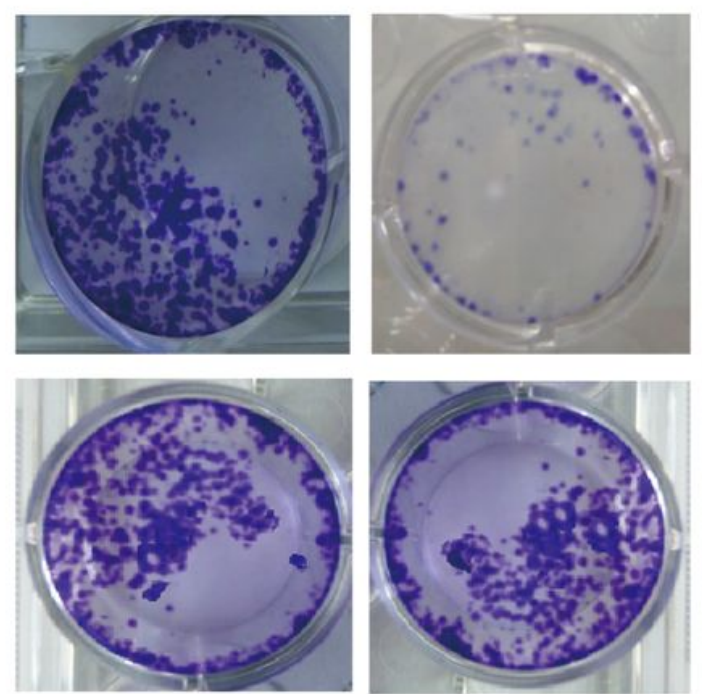

2.0
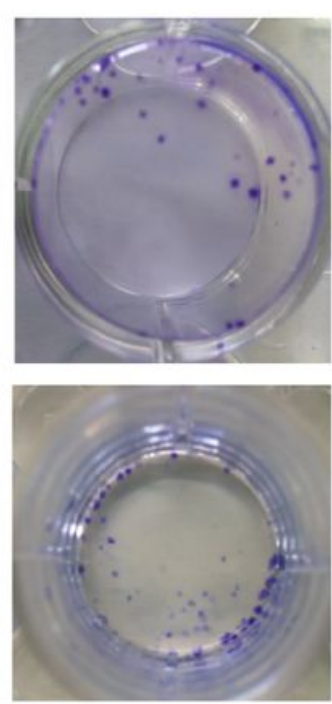

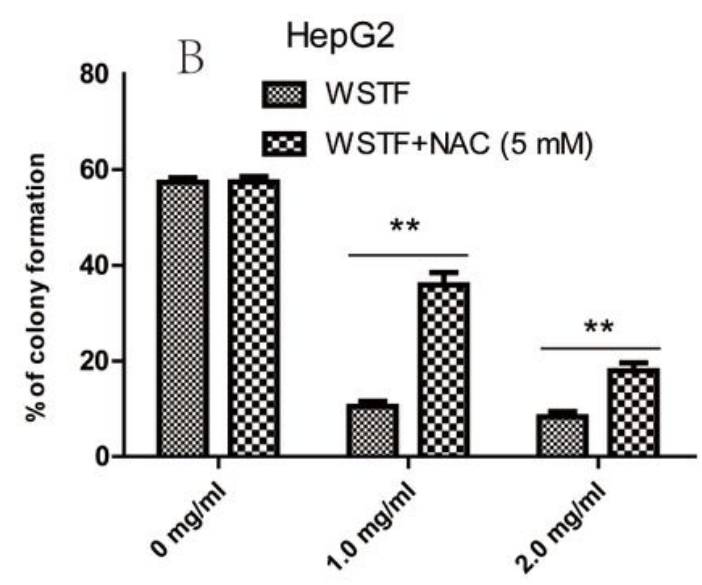

Figure 7

NAC inhibits the effect of WSTF on colony formation of HepG2 cells. After $1 \%$ crystal violet staining, each plate was photographed after 12 days. Then, the colony percentage was determined. 

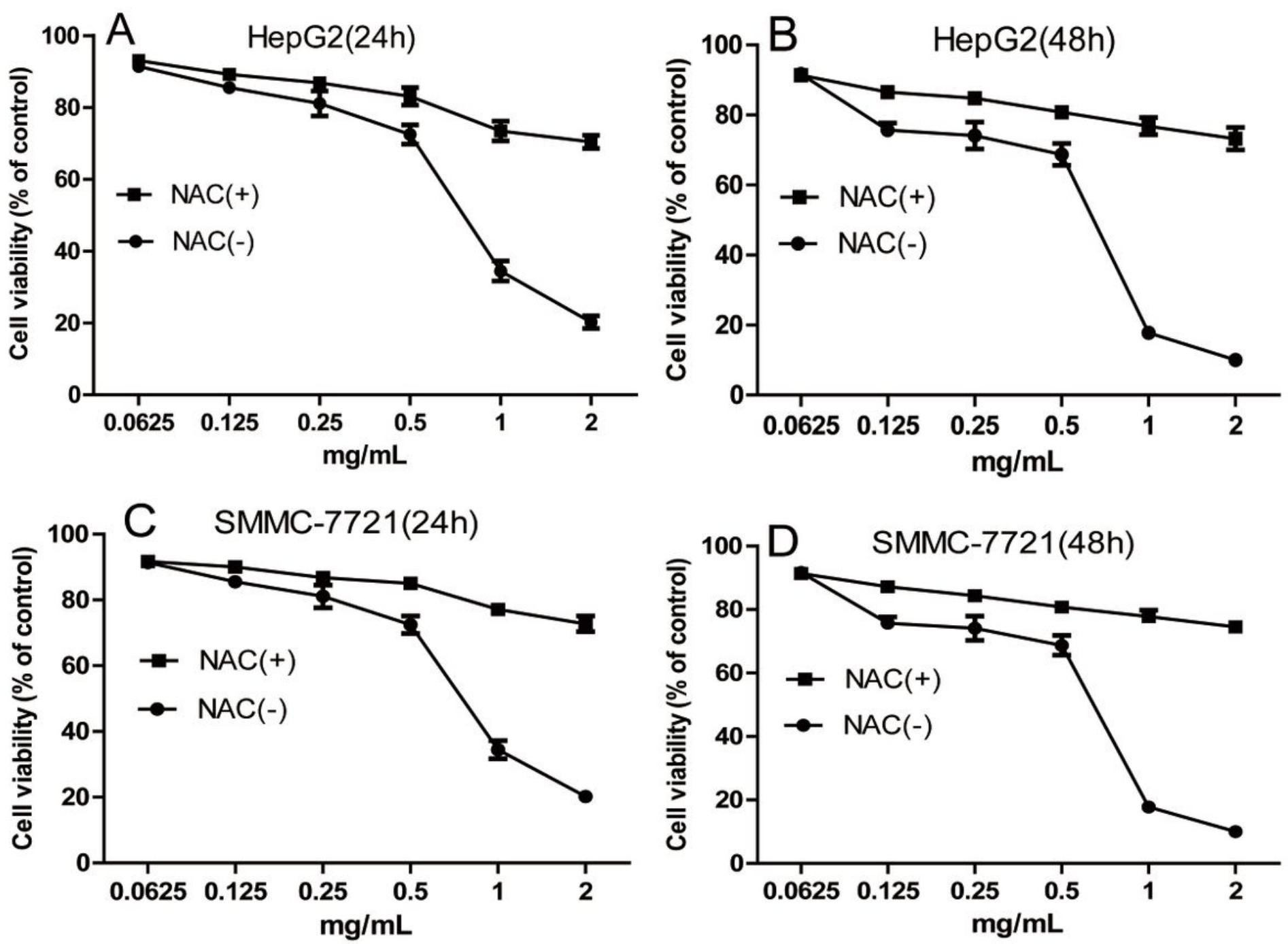

Figure 8

NAC weakens the inhibition of WSTF on cancer cell growth in HepG2 and SMMC-7721 cells After 1 h NAC treatment, cells were exposed to WSTF treatment for 24 and $48 \mathrm{~h}$, respectively. All results are expressed in the manner of mean \pm SEM from 3 independent tests. ${ }^{*} P<0.05,{ }^{*} P<0.01$ compared with controls. 
A

bcl-2

bax

PARP

Cle-PARP

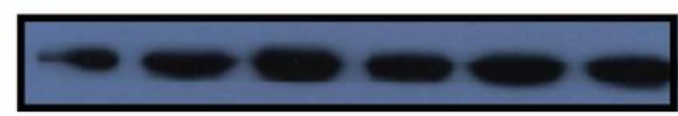

$\beta$-actin

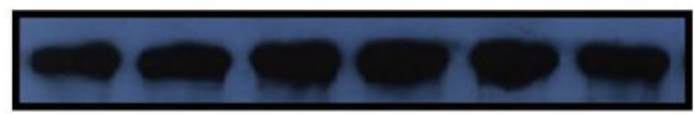

$\operatorname{WSTF}(\mathrm{mg} / \mathrm{ml}) \quad 0$

1.0

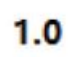

2.0

$\begin{array}{lll}0 & 1.0 & 2.0\end{array}$

$\mathrm{NAC}(5 \mathrm{mM})$

- -+++

\section{Cytosolic Alf}

B-actin

WSTF(mg/ml)

NAC(5mM)
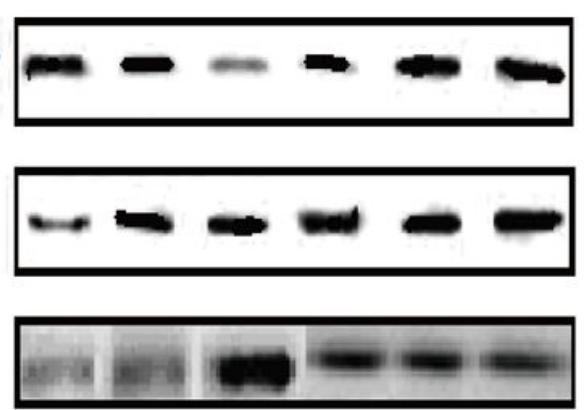

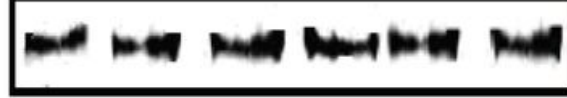

$\begin{array}{llllll}0 & 1.0 & 2.0 & 0 & 1.0 & 2.0\end{array}$

- . + + +

Figure 9

NAC inhibits the effect of WSTF on pro- and anti-proptotic protein levels. After $1 \mathrm{~h}$ of NAC pretreatment, HepG2 cells were exposed to WSTF for $48 \mathrm{~h}$.
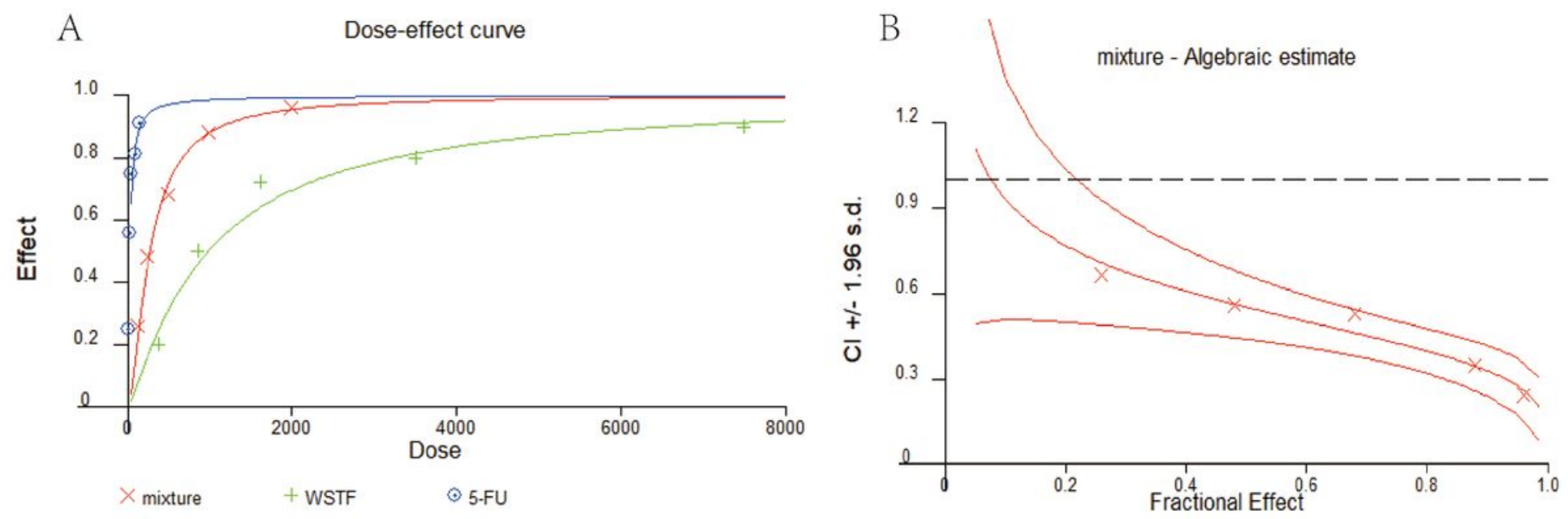

Figure 10

WSTF promotes 5-FU anticancer activity in vitro. A. 3000 cells/well were treated with WSTF plus 5-FU for MTT assay. The inhibition rates of WSTF and 5-FU on HepG2 cells were calculated $\mathrm{B}$. $\mathrm{Cl}$ values were calculated by CalcuSyn2.0. 

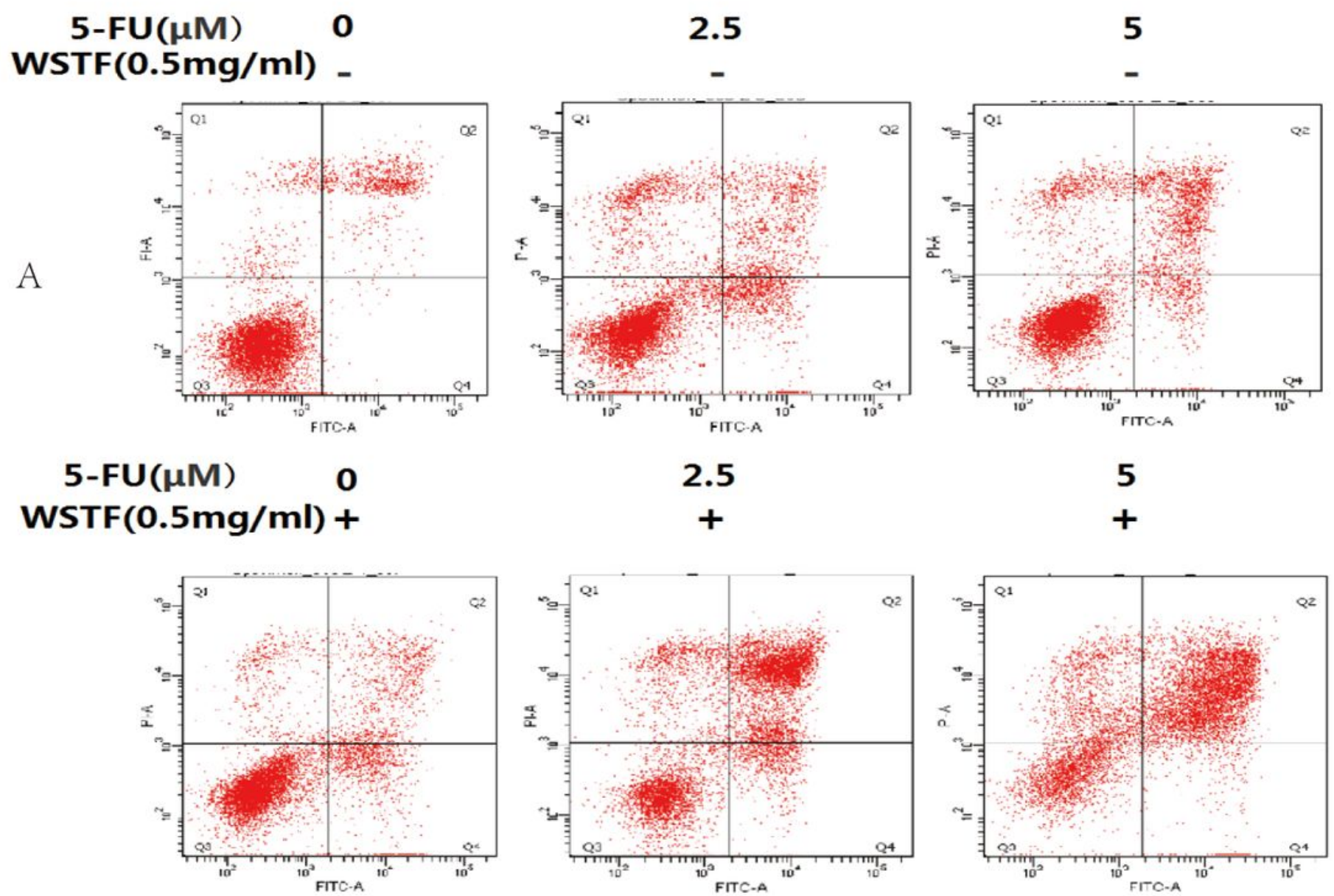

5

PI

C
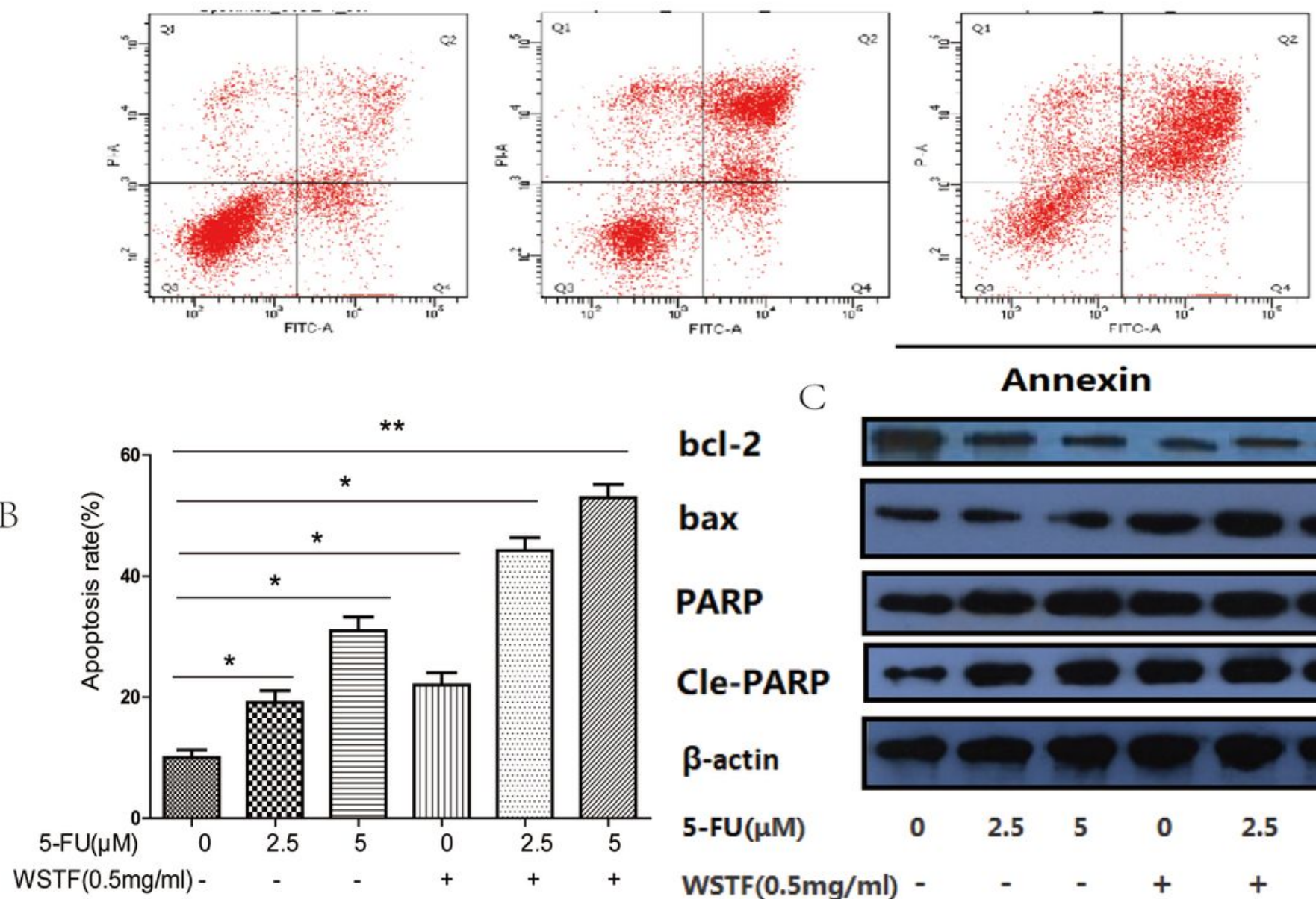

bcl-2

bax

PARP

Cle-PARP

$\beta$-actin

5-FU( $\mu M)$

0

Annexin

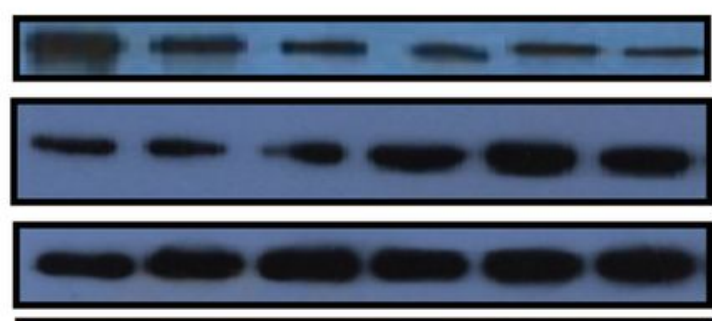

WSTF $(0.5 \mathrm{mg} / \mathrm{ml})$

\section{Figure 11}

Combination of WSTF with 5-FU induces apoptosis. A. HepG2 cells were subjected to Annexin V/PI staining for evaluating the WSTF and/or 5-FU-induced apoptosis. B. Cell apoptosis percentage were expressed in the manner of mean \pm SEM from 3 independent tests. C. The expression of apoptosisrelated proteins through Western blotting. ${ }^{*} P<0.05,{ }^{*} \mathrm{P}<0.01$. 


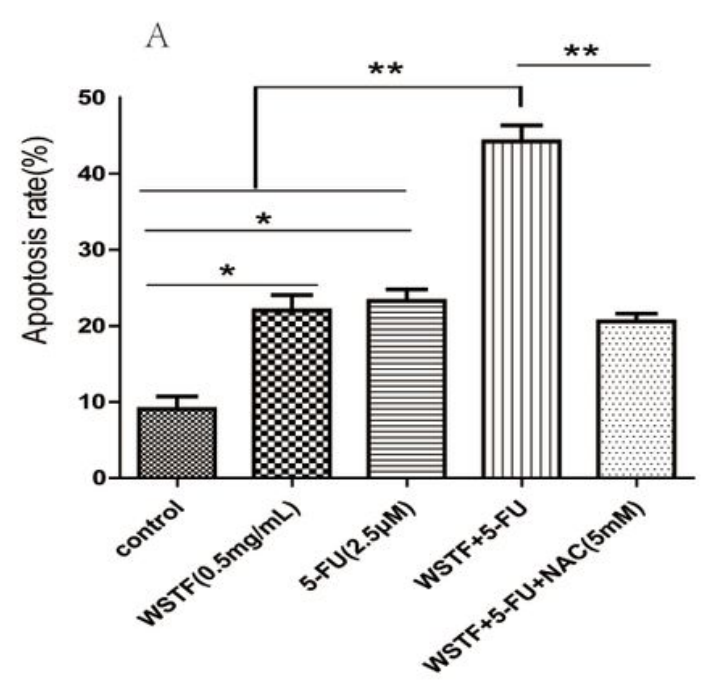

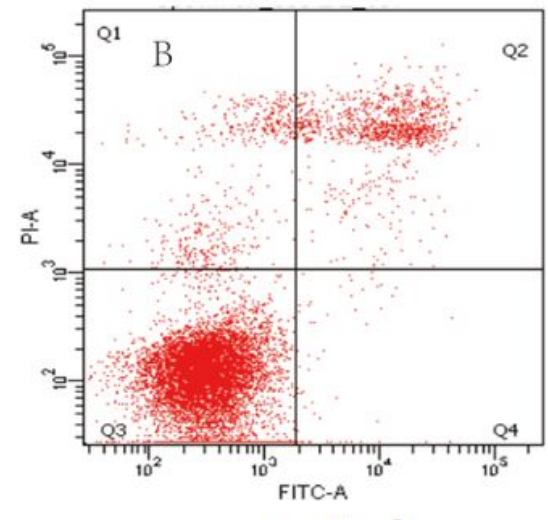

control

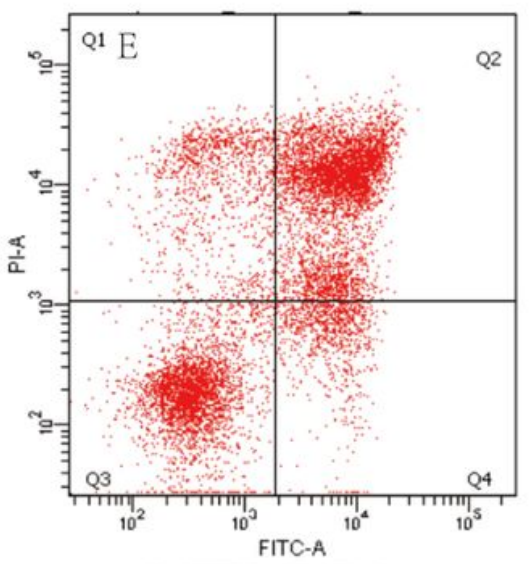

WSTF+5-FU

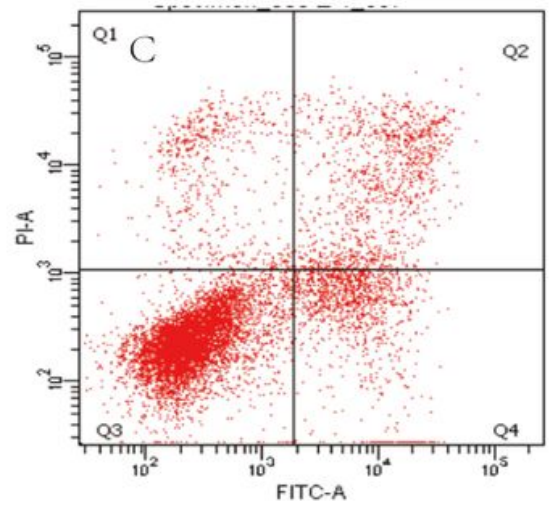

WSTF(0.5mg/ml)

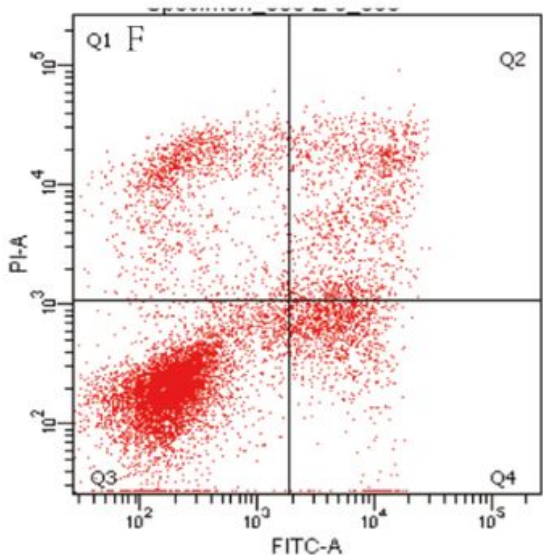

WSTF+5-FU+NAC(5mM)

Figure 12

NAC inhibits the impact of WSTF plus 5-FU on apoptosis. HepG2 cells were subjected to Annexin V/PI staining for evaluating apoptosis induced by WSTF plus 5-FU with or without NAC. 

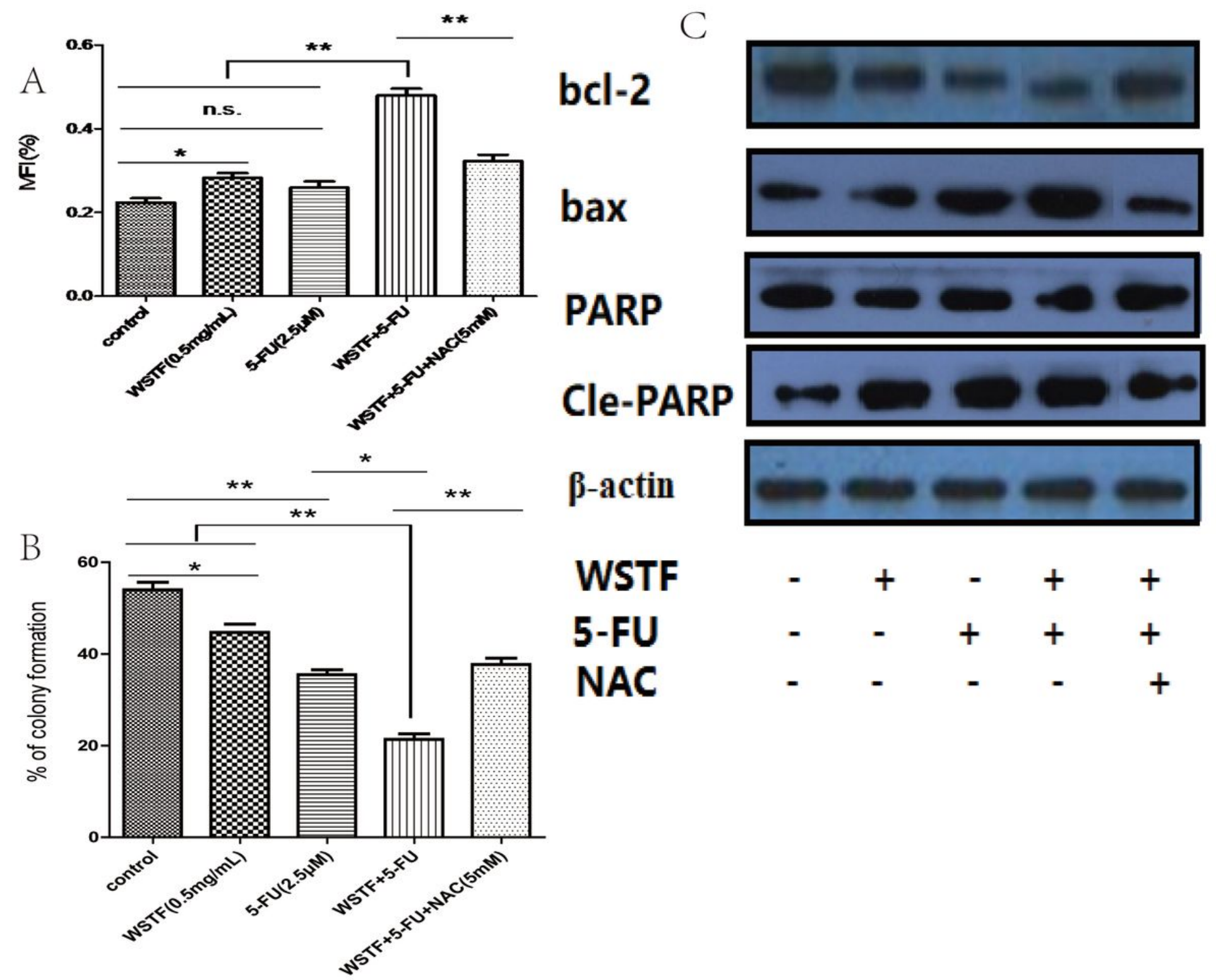

$\beta$-actin

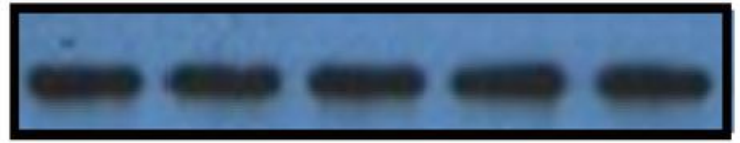

$-\quad+\quad-\quad+\quad+$

- $\quad+\quad+\quad+$

Figure 13

NAC inhibits the impact of WSTF plus 5-FU on ROS accumulation, colony formation, and apoptosisrelated protein expression within HepG2 cells. A. After $48 \mathrm{~h}$ of incubation with WSTF and 5-FU with or without NAC, ROS level in HepG2 cells was determined by DCFH-DA, and the relative intensity of average .uorescence is presented in the manner of mean \pm SEM from 3 independent tests. B. After $48 \mathrm{~h}$ of incubation with WSTF and 5-FU with or without NAC, After $1 \%$ crystal violet staining, each plate was photographed after 10 days. Colony percentage was determined and presented in the manner of mean \pm SEM from 3 independent tests. C. After $48 \mathrm{~h}$ of incubation with WSTF and 5-FU with or without NAC, The expression of apoptosis-related proteins by Western blotting. ${ }^{*} \mathrm{P}<0.05,{ }^{*} \mathrm{P}<0.01$. 


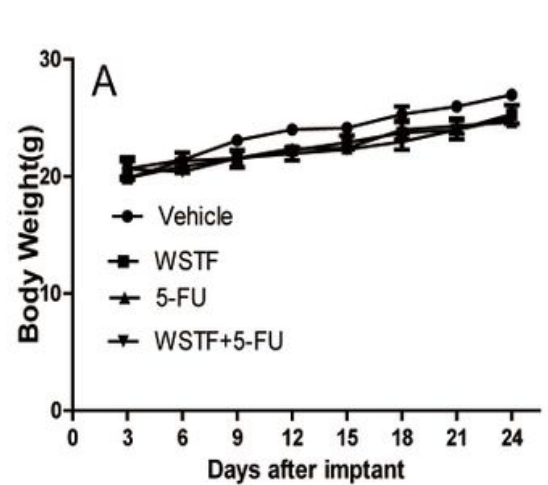

C Vehicle

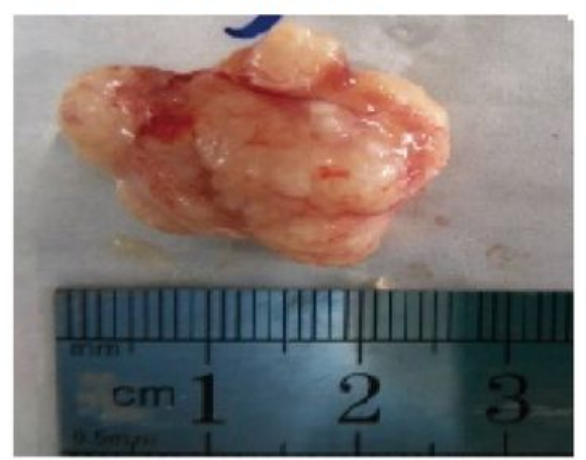

5-FU

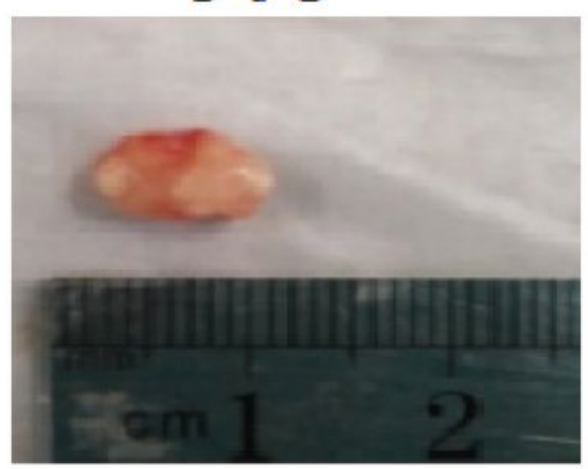

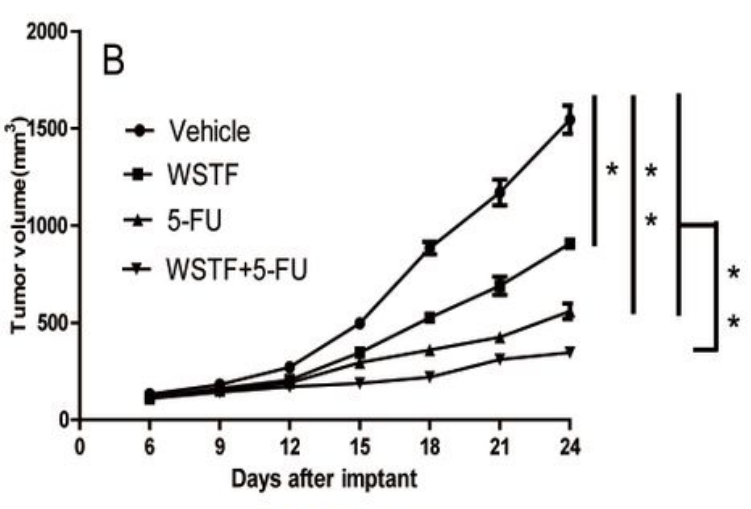

WSTF

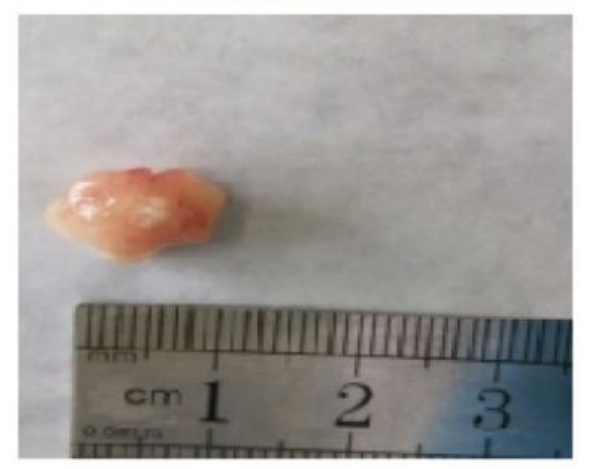

WSTF+5-FU

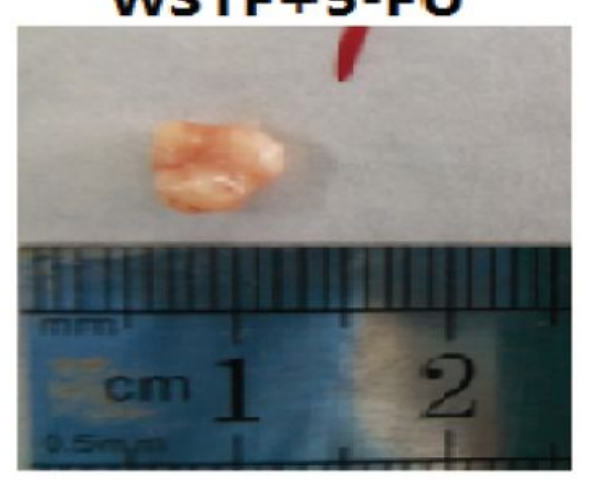

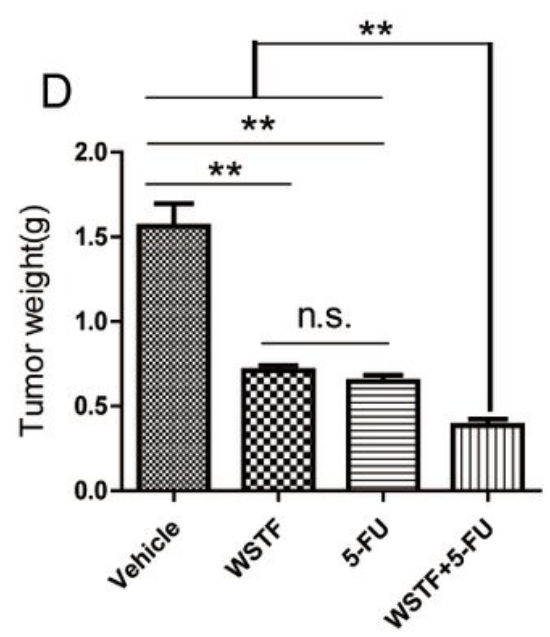

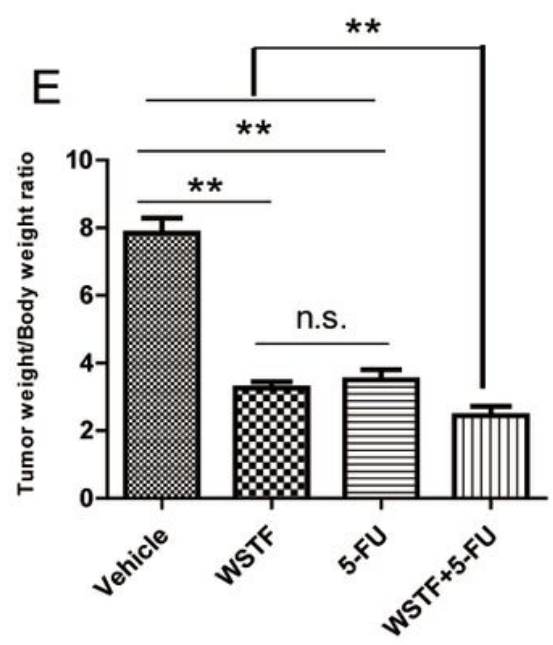

\section{Figure 14}

WSTF promotes anticancer activity of 5-FU in vivo A. Body weight curves of mice in each group. Combination treatment with WSTF and 5-FU did not affect the nude mouse body weight B. Xenograft growth curve. Subcutaneous injection of HepG2 cells was given to mice through oxter (xenograft volume was determined at intervals of 3 days) and drug administration started. C. The specimen of xenografts among four groups. D. Tumor weights of four groups. E. Tumor /body weight ratio in the four groups. Results are expressed in the manner of mean \pm SEM from 3 independent tests. ${ }^{*} P<0.05,{ }^{*} P<0.01$, n.s. no significance. 
A
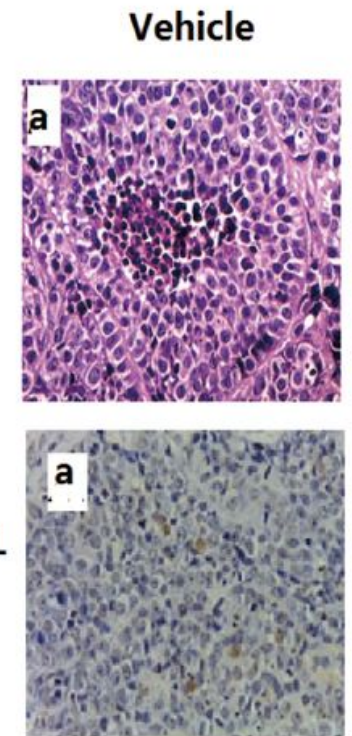

WSTF
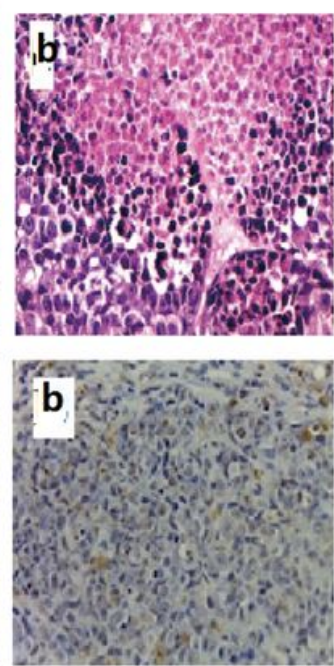

5-FU
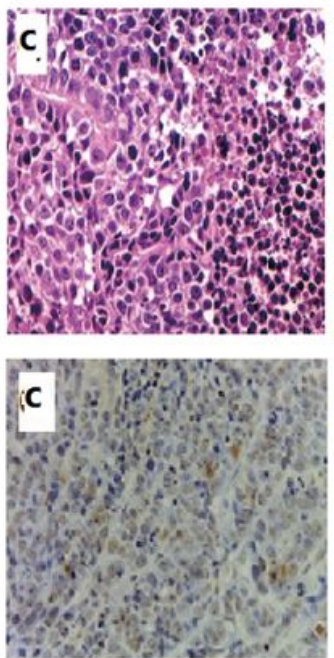

WSTF+5-FU
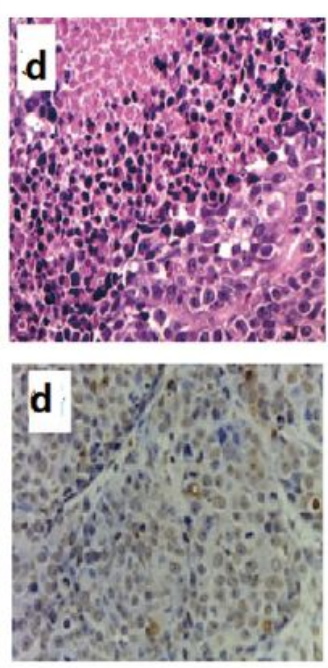

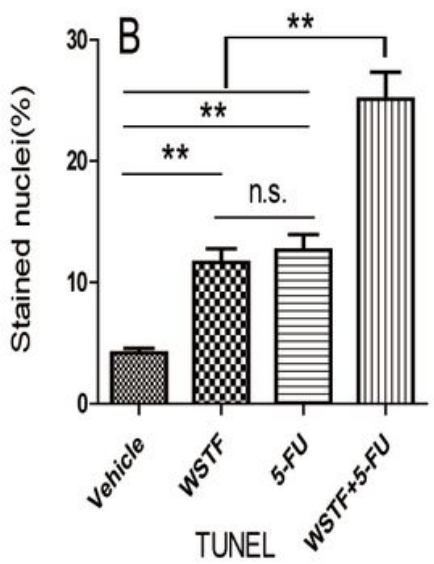

Figure 15

H\&E staining. A. Hematoxylin of HepG2 cell xenografts in nude mice (HEx200) and TUNEL assay $(\times 40)$ for xenografts. B. TUNEL stained nucleus percentage was used to evaluate apoptosis by TUNEL staining. Results are expressed in the manner of mean \pm SEM from 3 independent tests. ${ }^{*} P<0.05,{ }^{*} P<0.01$, n.s. no significance. 